\title{
Epigenetic crosstalk between hypoxia and tumor driven by HIF regulation
}

\author{
Tiansheng $\mathrm{Li}^{1,2}$, Chao Mao ${ }^{1,2}$, Xiang Wang $^{3}$, Ying Shi ${ }^{1,2^{*}}$ and Yongguang Tao ${ }^{1,2,3^{*}}$ (D)
}

\begin{abstract}
Hypoxia is the major influence factor in physiological and pathological courses which are mainly mediated by hypoxia-inducible factors (HIFs) in response to low oxygen tensions within solid tumors. Under normoxia, HIF signaling pathway is inhibited due to HIF-a subunits degradation. However, in hypoxic conditions, HIF-a is activated and stabilized, and HIF target genes are successively activated, resulting in a series of tumour-specific activities. The activation of HIFs, including HIF-1a, HIF-2a and HIF-3a, subsequently induce downstream target genes which leads to series of responses, the resulting abnormal processes or metabolites in turn affect HIFs stability. Given its functions in tumors progression, HIFs have been regarded as therapeutic targets for improved treatment efficacy. Epigenetics refers to alterations in gene expression that are stable between cell divisions, and sometimes between generations, but do not involve changes in the underlying DNA sequence of the organism. And with the development of research, epigenetic regulation has been found to play an important role in the development of tumors, which providing accumulating basic or clinical evidences for tumor treatments. Here, given how little has been reported about the overall association between hypoxic tumors and epigenetics, we made a more systematic review from epigenetic perspective in hope of helping others better understand hypoxia or HIF pathway, and providing more established and potential therapeutic strategies in tumors to facilitate epigenetic studies of tumors.
\end{abstract}

Keywords: Hypoxia, Hypoxia-inducible factors (HIFs), Tumors, Epigenetic regulation, Crosstalk, Therapeutic strategy

\section{Background}

Low oxygen tension (hypoxia) arises from excessive oxygen consumption to supports the demand of rapid proliferation, and abnormalities in the structure and function of blood vessels within solid tumors [1-4]. Mounting clinical and experimental evidences have revealed that hypoxia-related oxygen pressure contributes to higher metastasis and mortality rates [5-7]. Hypoxia occurs in $90 \%$ of solid tumors, which has been regarded as a hallmark of cancer [8-10]. In addition, hypoxia often plays a key role in tumor progression and tolerance to targeted therapies [11, 12]. Massive efforts have

\footnotetext{
*Correspondence: yingshi@csu.edu.cn; taoyong@csu.edu.cn

${ }^{1} \mathrm{NHC}$ Key Laboratory of Carcinogenesis and Hunan Key Laboratory of Translational Radiation Oncology, Hunan Cancer Hospital and The Affiliated Cancer Hospital of Xiangya School of Medicine, Central South University, Changsha, Hunan, China

Full list of author information is available at the end of the article
}

been brought about in investigating hypoxia due to its significantly clinical implication.

Tumor-associated metabolic alterations at multi-steps of metastasis have been observed in clinical samples via ever-accelerated updating of molecular biological tools. Particularly, it has become evident that adaptation in metabolite-driven gene regulation may be a potent hallmark to measure tumorigenesis [13-15]. Hypoxiainducible factors (HIFs) are heterodimers composed of $\alpha$ subunits and $\beta$ subunits, where $\alpha$ subunits include HIF$1 \alpha$, HIF- $2 \alpha$, and the less studied HIF-3 $\alpha$ [12, 16, 17]. Under normoxia, two prolines residues of HIF- $1 \alpha$ and HIF- $2 \alpha$ are hydroxylated by prolyl hydroxylase domain protein 2 (PHD2) and go through ubiquitin-mediated proteolysis via binding to Hippel-Lindau tumor suppressor (VHL) [18]. However, these ubiquitination processes are inhibited due to enzyme inactivation within solid 
tumors, which leading to accumulating HIF- $1 \alpha$ and HIF$2 \alpha$ stability [19]. HIF-1, existing in the form of functional heterodimer which consisting of $\alpha$ and $\beta$ (aryl hydrocarbon receptor nuclear translocator, ARNT) isoforms, is a primary sensor of oxygen limitation and its induction supports cancer cells proliferation during hypoxia by eliciting several metabolic alterations [4, 20]. Likely, HIF$2 \alpha$ /ARNT heterodimer, known as HIF-2, is sensible to oxygen availability in tumors, and is also tightly controlled by proteasomal degradation via prolyl hydroxylases (PHDs) in both normoxic and hypoxic conditions [21]. Moreover, HIF- $2 \alpha$ promotes tumor progression via macrophage lactate /HIF-2 $\alpha / \mathrm{ATP} 6 \mathrm{v} 0 \mathrm{~d} 2$ axis [22], and some lncRNAs may be its transcriptional targets within solid tumors [21]. Role of HIF-3 $\alpha$ has not yet been fully understood, which has long been thought negatively associated with HIF- $1 \alpha$ and HIF- $2 \alpha$ expression and function to directly or indirectly regulate hypoxia-induced pathological processes [23-25]. For example, TIMP2 (tissue inhibitor of metalloproteinases 2) blockade by HIF- $1 \alpha /$ miR-210/HIF- $3 \alpha$ feed circuit often plays a significantly role in regulating hepatocellular carcinoma (HCC) metastasis, which is regard as associated with poor prognostic effects [26].

HIF signaling directly or indirectly get a tightly command of physiological and pathological functions of numerous genes associated with carcinogenesis mechanisms, which refer to the regulation of proliferation, cell death, radiotherapy and chemotherapy $[24,25$, 27-30], tumor microenvironment [31-33], metastasis [34-36], angiogenesis [37-40], and metabolic reprogramming [41-43] etc. within solid tumors. Epigenetics refers to a heritable change in gene expression when DNA sequence is not changed, that is, the genotype is not changed but the phenotype is changed $[44,45]$. It's an out-of-sequence form of inheritance. In addition to the genetic information provided by DNA sequence, epigenetic information provides instructions on when, where and how to apply genetic information such as DNA methylation, histone modification, and nucleosome positioning [44]. Epigenetic research has been an important part of cancer research providing accumulating basic or clinical evidences for tumor treatments [46, 47]. In the present review, we put our eyes on the role of HIF signaling and hypoxia-dependent regulator in tumor progression from the perspective of epigenetics.

\section{Canonical and non-canonical regulation of HIF signaling}

HIF family mainly mediates cellular oxygen tensiondependent reactions via a basic helix-loop-helix structure with a significant implication in pathological processes in tumors $[4,48]$. It's reported that HIF- $1 \alpha$ and HIF- $2 \alpha$ are widely expressed in various cell types and special tissues, respectively [49]. In the state of canonical regulation, HIF signaling is activated transcriptionally by the binding of HIF- $1 \alpha$ or HIF- $2 \alpha$ to their selective binding partner HIF-1 $\beta[4,11]$. In the normoxic case, the oxygen-dependent degradation (ODD) domain within HIF- $1 \alpha$ confers instability for HIF- $\alpha$ function [50]. The ODD module will be degraded via binding with VHL which playing a role of E3 ubiquitin ligase complex in part through ubiquitin-proteasome pathway. In detail, prolyl hydroxylases (PHDs) catalyze the hydroxylation of ODD domain which is recognized by VHL, eventually leading to proteasomal degradation of HIF- $\alpha$ (Fig. 1a) [51]. With that in mind, inactivation of VHL, including mutations and other modifications such as methylation, is associated with various illnesses such as clear-cell renal cell carcinoma (ccRCC) due to aberrant VHL/HIF axis and may also affects human phenotypes [52, 53]. VHL encodes two RNA (variant 1 and variant 2), three different protein isoforms (pVHL213, pVHL160 and pVHL172). The pVHL213 and pVHL160 is translated from variant 1 through alternative splicing, and pVHL172 from variant 2. Recently, relevant studies revealed that pVHL172 is not involved in HIF signaling other than pVHL213 and pVHL160 [54, 55]. Oxygen concentration-dependent mechanism involving PHDs, exhibits a canonical example to perform response to hypoxia. In addition, under normoxia, an asparagine residue in the C-terminal activation domain of HIF- $1 \alpha$ and HIF- $2 \alpha$ is hydroxylated by factor inhibiting HIF (FIH), resulting in the inability of the region to bind to p300, thus weakening the activation of the HIF pathway. However, in hypoxia, due to the inactivation of FIH, HIF- $1 \alpha$ and HIF- $2 \alpha$ avoid being hydroxylated, and subsequently translocate into the nucleus to bind with ARNT and p300, leading to the activation of HIF target genes [56]. The effect of FIH on the HIF- $\alpha$ further deepens our understanding of the mechanisms governing the stability of HIF- $\alpha$.

However, in mionectic cells, including hypoxic tumor cells and stromal cells, condition is characterized by non-canonical signaling pathway [11]. Metabolic reprogramming of tumor cells is characterized by the balance of glycolysis and oxidative phosphorylation (OXPHOS), and the interaction between the crosstalk and HIF signaling, especially HIFs stability is largely unclear [57]. OXPHOS damage is ever known to promote HIF- $1 \alpha$ stabilization in normoxia and hypoxia, however, a series of studies noted that OXPHOS damage accompanied with mitochondrial complex I (CI) dysfunction may reduce HIF- $1 \alpha$ activity, and glycolysis reduced by $5^{\prime}$ AMPactivated protein kinase (AMPK) is negatively associated with HIF- $1 \alpha$ activity due to ATP supply and reactive oxygen species (ROS) production which promotes tumor progression [58-61]. Besides the regulation of OXPHOS 

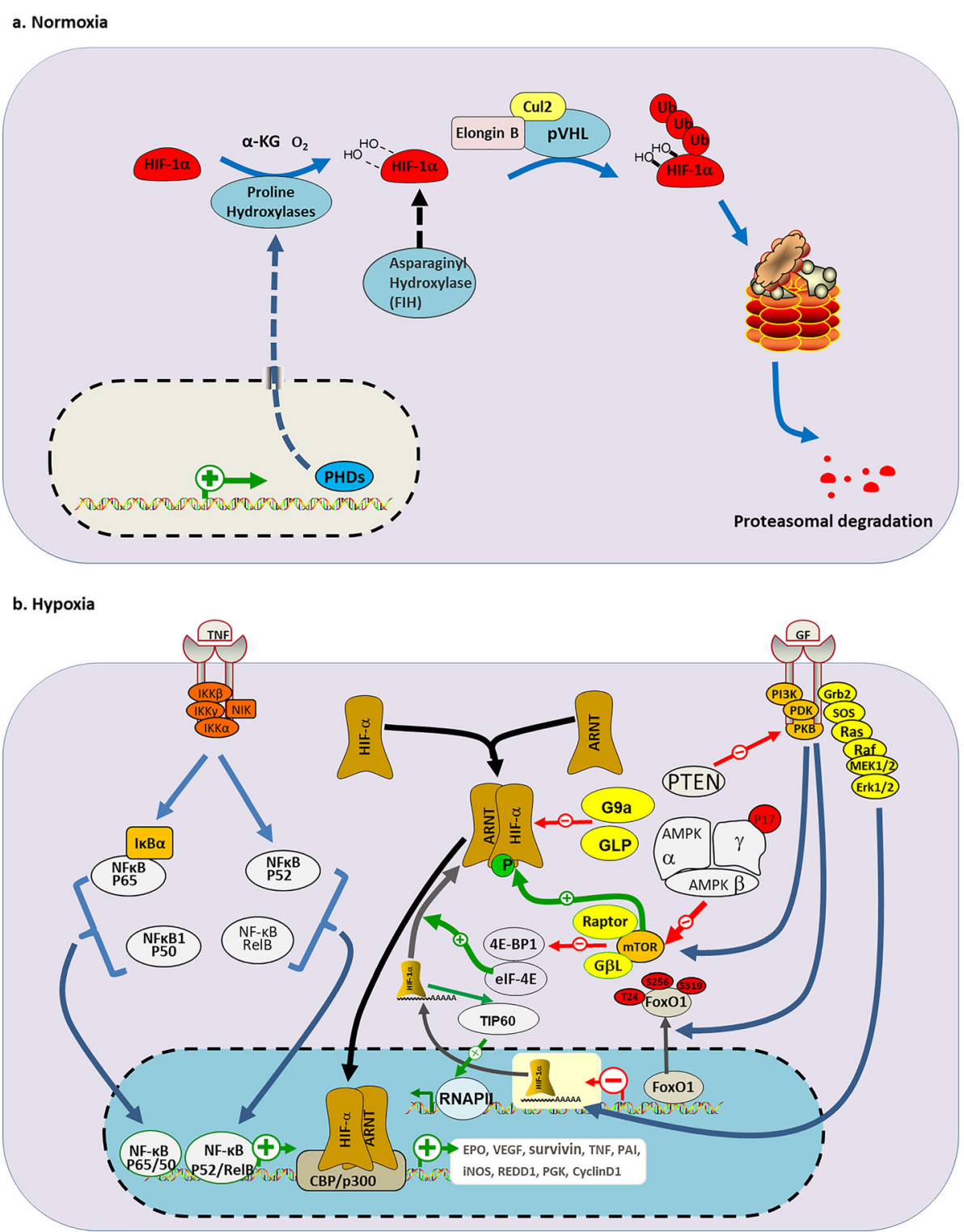

Fig. 1 Canonical and non-canonical regulation of HIF signaling. a Oxygen- dependent regulation of HIF-a. Under normoxic condition, the ODD module within HIF-1a will be degraded via binding to VHL E3 ubiquitin ligase complex which consisting of pVHL, Cullin 2 (Cul-2) and Elongin B. This process is mediated by ubiquitin-proteasome pathway, which a-ketoglutarate-dependent PHDs catalyze the hydroxylation of ODD domain which is recognized by VHL, eventually leading to proteasomal degradation of HIF-a. More, factor inhibiting HIF (FIH) inhibits the binding of p300 to HIF-a by hydroxylating asparagine residue within C terminal domain, which play a role of inhibition on HIF-a activity. b Regulation of the HIF pathway at mRNA and protein level. In hypoxic conditions, inhibition of PHDs promote the heterodimer formation consisting of HIF-a and ARNT. Extracellular signaling TNF-a stimulates I-KB kinase (IKK) complex which is comprised of IKKa and IKK $\beta$, and other normal TNF signaling (NIK), which contribute to p65/50 complex and p52/RelB complex formation. Many other components NF-KB together activate target genes, including HIF-a, and further induce inflammation. More, PI3K, PDK and PKB activation induced by growth factors (GFs) activates mTOR pathway results in elevated HIF-a transcriptional activity. And phosphorylation of FoxO1 PI3K/PKB, which is transferred from the nucleus to the cytoplasm, prevents FoxO1 from acting on HIF-a. G9a/GLP methylates HIF-1a protein and inhibits HIF-1a activity within solid tumors, making it unable to bind to the hypoxic response element (HRE) of its target genes, resulting in inhibition of the downstream HIF pathway. More, HIF-1a acts on TIP60, which leads to chromatin histone acetylation and then to the activation of polymerase II, which ultimately activates HIF-1a target genes transcription. IKB, nuclear factor of KB inhibitor, alpha; IKK, IKB kinase; 4EBP1, eukaryotic translation initiation factor 4E-binding protein 1; elF-4E, eukaryotic translation initiation factor; GßL: G protein beta subunit-like; Grb2: growth factor receptor-bound protein 2; EPO: erythropoietin; PAl: plasminogen activator inhibitor; iNOS: nitric oxide synthase; REDD1: regulated in development and DNA damage response 1; PGK: phosphoglycerate kinase 
genes, HIF-1 may be affected by many other factors, including hormones, growth factors and cytokines etc. on transcriptional and post-transcriptional level [62]. Increasing studies have elucidated that HIF genes could be regulated in the NF- $\mathrm{BB}$ (nuclear factor kappa-B) dependent manner. Some think that NF- $k B$ pathway is activated by TNF- $\alpha$ (tumor necrosis factor alpha) when relevant components of this pathway translocated into nucleus, and subsequent changes are performed on HIF$1 \alpha$ level [63-65]. Others demonstrated that HIF-1 $\beta$ would be modulated directly by TNF- $\alpha$ after the adaptation of $\alpha$ subunit, all this finally led to changed HIF- $2 \alpha$ gene expression in the presence of inflammatory cytokines, such as tat-associated kinase complex catalytic subunit (TAK), I-kappaB kinase (IKK) and cyclindependent kinase 6 (CDK6) [65-67]. More interestingly, authentic study has noted that TNFSF14 (tumor necrosis factor superfamily, member 14), as a non-canonical inducer of NF- $\mathrm{kB}$, could perform a direct alteration on HIF- $2 \alpha$ expression and activity. Mechanistically, TNFS F14-induced p52 selectively binds with certain sites of HIF- $2 \alpha$ promoter leads to elevation of HIF- $2 \alpha$ expression [68] v. In addition to the TNF signaling, PI3K/Akt/ mTOR pathway also play a significant role in regulating HIFs activity, for example, phosphoinositide 3-kinase (PI3K), pyruvate dehydrogenase kinase (PDK) and protein kinase $\mathrm{B}(\mathrm{PKB})$ activation induced by growth factors activate mammalian target of rapamycin (mTOR) pathway results in elevated HIF- $\alpha$ transcriptional activity. And phosphorylation of forkhead box protein $\mathrm{O} 1$ (FoxO1), which is transferred from the nucleus to the cytoplasm, prevents FoxO1 from acting on HIF- $\alpha$ (Fig. 1b) $[19,69]$. Recent studies have shown that upregulated expression of interleukin-1 $\beta$ (IL-1 $\beta$ ) secreted by $B$ cells promotes the activation of HIF- $2 \alpha$, and HIF- $2 \alpha$ activation further promotes the activation of delta like canonical Notch ligand 4 (DLL4) signaling, and finally interact with neurogenic locus notch homolog (Notch) to form the IL-1 $\beta /$ HIF- $2 \alpha /$ Notch 1 axis [70]. Collectively, various mechanisms drive HIF signaling activation in low oxygen tensions to maintain the state of various cancer cell types, and TNF- $\alpha$ interacts with HIF signaling provides a preferable and typical example.

\section{Epigenetic regulation of HIFs activity}

Growing evidence has revealed that the transcriptional activity of HIFs is regulated by epigenetic factors at multiple levels $[71,72]$. The stability of HIF- $\alpha$ subunits are the basis for biological function of HIF complexes and regulates hypoxia-related phenotypes of tumor cells in combination with other important epigenetic regulators [73]. Lots of different epigenetic factors, including enzymes that play a role in methylation and acetylation, and non-coding RNAs, are closely related to HIFs stability and transcriptional activity [74].

\section{Effects of DNA methylation and demethylases on HIF-a activity}

DNA methylation is an important event of epigenetic regulation within hypoxic tumors [45]. DNA methylation is a process in which S-adenosylmethionine (SAM) is used as a methyl donor to transfer methyl groups to specific bases under the catalysis of DNA methyltransferase $[75,76]$. But in human cancers, DNA methylation occurs mainly at cytosine of CpG sites to produce 5methylcytosine $(5 \mathrm{mC})$ [77, 78]. DNA methylation can regulate HIFs stability, and subsequently influence HIFs target genes expression [2]. Among them, promoter hypermethylation could lead to tumor suppressor genes silencing in cancer [79]. For instance, VHL hypermethylation at promoter site increases transcriptional activation of HIF- $1 \alpha$ and promotes HIF- $1 \alpha$ target gene activation such as carbonic anhydrase 9 (CA9) and glucose transporter type 1 (GLUT1) [2, 80]. DNA demethylation is also associated with dynamic regulation of HIF- $1 \alpha$. For example, HIF- $1 \alpha$ promoter is demethylated at $\mathrm{CpG}$ site within colon cancer, which promoting the binding of HIF- $1 \alpha$ protein to its own promoter and thus affecting HIF-1 $\alpha$ transcriptional activation and target genes activation $[2,81]$. DNA demethylation mediated by ten-eleven-translocation 5-methylcytosine dioxygenases (TET) plays an important role in regulating hypoxia-induced transcriptional program [82]. The 2oxoglutarate-dependent dioxygenases (2-OGDDs) is a large family of about 70 members, of which the TET1-3 proteins are important members [83]. The TET proteins has the function of hydroxylation, which converts the $5 \mathrm{mC}$ in DNA to 5-hydroxymethylcytosine $(5 \mathrm{hmC}), 5$ formylcytocine, and 5-carboxylcytocine, leading to DNA demethylation in the consecutive biochemical reactions $[84,85]$. However, it is the protein-protein interaction between TETs and other proteins, rather than the dependence of TET's demethylase activity, that regulates the functional activity of HIF- $\alpha$ [75]. For example, $5 \mathrm{hmC}$ mediated by TET1 enzyme has been regarded as an important epigenetic DNA modification in brain, and can interacts with HIF- $1 \alpha$ protein to regulate the responses induced by chronic restraint stress (CRS) in mice with CRS-induced depressive phenotype [86, 87]. Cheng et al. found that deletion of the TET1 gene resulted in CRS resistance in mice, conversely, and that the stressinduced hydroxymethylated loci (SI-DhMLs) were enriched with HIF- $1 \alpha$ binding regions via genome-wide profiling [86]. Then, they identified that the elevated HIF-1 $\alpha$ binding under CRS is related to SI-DhMLs through biochemical and chromatin immunoprecipitation sequencing (ChIP-seq) [87]. Together, these results 
shows that TET1 enzyme regulates stress-induced response by interacting with HIF-1 $\alpha$ protein [87]. These results suggest that TET1 can regulate biochemical reactions by interacting with HIF- $1 \alpha$, rather than directly depending on DNA demethylase activity of TET1 on HIF$1 \alpha$ in non-tumor cells [87]. The interaction of TET1 with HIF- $1 \alpha$ has also been further confirmed in neuroblastoma [88]. Hypoxia elevates global $5 \mathrm{hmC}$ level in DNA, and high level of $5 \mathrm{hmC}$ is closely related to the active expression of hypoxia-responsive target genes [82]. Part of the $5 \mathrm{hmC}$ was colocated with the hypoxic response element (HRE), promoting DNA demethylation and HIF binding [2]. Hypoxia leads to transcriptional activation of TET1 in HIF-1 dependent manner, and TET1 enzyme increases global $5 \mathrm{hmC}$ level [88]. These results suggest that TET1-mediated $5 \mathrm{hmC}$ alterations play an important role in the hypoxic response via HIF-1 binding rather than DNA demethylation of HIF-1 $\alpha$ [88].

\section{The $\mathrm{m}^{6} \mathrm{~A}$ methylation of mRNA involves in epigenetic regulation of HIF- $\alpha$ activity}

To some extent, N6-methyladenosine $\left(\mathrm{m}^{6} \mathrm{~A}\right)$ methylation can also regulate the stability of HIF- $\alpha$ within tumor cells. The $\mathrm{m}^{6} \mathrm{~A}$ methylation on the 6th position of RNA molecule adenine, is the most common posttranscriptional modification of eukaryotic mRNA, occurring in about $25 \%$ of transcripts at genomic level [8991]. For example, affects the methylation status of HIF$2 \alpha$ mRNA. As the $\mathrm{m}^{6} \mathrm{~A}$ site identifier and RNA-binding protein, MTHFD2 is mainly involved in specific recognition of $\mathrm{m}^{6} \mathrm{~A}$-modified mRNAs in the cytoplasm, including $\mathrm{m}^{6} \mathrm{~A}$ methylation of HIF-2 $\alpha$ mRNA $[92,93]$. MTHF D2 leads to increased stability of HIF- $2 \alpha$ mRNA, which further improve HIF-2 $\alpha$ translation [92]. Increased HIF$2 \alpha$ translation, in turn, elevates the transcriptional activity of MTHFD2 and finally results in a series of metabolic alterations [92]. This suggests that other m6A methylases may also be related to the stability of HIFs, but the epigenetic mechanisms remain to be further studied.

\section{Histone methylation and demethylation affect HIF-a activity}

At present, histone methylation has been gradually recognized as an important regulatory factor driving malignant transformation of hypoxic tumors [94]. For example, G9a and G9a-like protein (GLP), as histone lysine methylases, regulate HIF- $1 \alpha$ transcriptional activity and drive hypoxic-induced genes regression (Fig. 1b) [94, 95]. G9a, encoded by euchromatic histone lysine methyltransferase 2 (Ehmt2) mRNA, is an epigenetic regulator that methylates histone $\mathrm{H} 3$ lysine 9 (H3K9) and leads to condensed chromatin [96]. Since G9 is genetically down-regulated in a variety of tumors and can inhibit the expression of tumor suppressor genes, it plays an important role in carcinogenesis [2, 95]. The stability of G9a protein is increased due to the reduction of prolyl hydroxylation, which reducing the interaction between G9a and pVHL and subsequent proteasomal degradation [95]. A subset of genes which are necessary for hypoxic tumor suppression, are repressed due to increased H3K9 methylation by G9a [95]. And an G9a inhibitor, BIX01294, decreases the levels of PHD2, pVHL and vascular endothelial growth factor (VEGF), leading to increased stability of HIF- $1 \alpha$ protein and reduced angiogenic activity [97]. However, the direct regulatory effects of G9a on HIF- $1 \alpha$ and even HIF- $2 \alpha$ remain unclear. GLP generally plays a synergistic epigenetic modification function with G9a in tumors [94, 98]. For example, H3K9 methylation mediated by G9a and GPL enzymes depends on the functional activity of $\mathrm{FIH}$. Under normoxic conditions, G9a and GLP were hydroxylated by FIH at the Asn779 and Asn867, respectively. After hydroxylation, G9a and GLP lost the function of methylating H3K9 [99]. Under hypoxic conditions, G9a and GLP proteins were not hydroxylated, thus maintaining stability, resulting in H3K9 methylation with inhibitory effect on genes, and finally realizing the epigenetic regulation of FIH-G9a/GLP signaling axis on the invasion and metastasis of ovarian cancer [99]. FIH also has similar regulatory effects on HIF- $1 \alpha$ and HIF- $2 \alpha$ in physiological and pathological conditions [56]. Whether this indicates that G9a/GLP has direct effects on HIF- $\alpha$ activities via epigenetic regulation are still unknown. What we know is that G9a/GLP bind directly to HIF-1 $\alpha$ protein in hypoxic tumors, both in vitro and in vivo, and catalyze monomethylation and dimethylation of HIF- $1 \alpha$ at lysine 674, thereby inhibiting the transcriptional activity of HIF- $1 \alpha$ and the expression of its downstream target genes [72]. For histone demethylases, the Jumonji domain (JMJD) containing protein and lysine-specific demethylase 1 (LSD1) involved in regulation of HIF stability [100]. The proteins of the Jumonji C (JmjC) containing family are mainly composed of 2-oxoglutarate (2OG) - and $\mathrm{Fe}^{2+}$-dependent histone demethylase, of which JMJD6 is an important member [101]. In recent years, JMJD6 has been thought to be related to the occurrence and development of a variety of tumors, including breast cancer, melanoma, oral cancer, glioblastoma, hepatocellular carcinoma, colon cancer, ovarian cancer and neuroglioma [101-110]. For instance, in ovarian cancer, Zheng et al. found that JMJD6 was highly expressed in tumor cells by tissue microarray immunohistochemical staining, and the high expression was associated with poor prognosis of patients [108]. According to the crystal structure characteristics of JmjC, they designed a JMJD6 inhibitor SKLB325, and tested the efficacy of the drug in vitro and in vivo, the results 
showed that the efficacy was good [108]. LSD1 is an flavin adenine dinucleotide (FAD)-dependent histone lysine demethylase, which can remove monomethyl or dimethyl from lysine 3 and lysine 9 of the histone 3 [100]. Abnormal LSD1 expression can be seen in a variety of cancers, such as blood, neuronal, thyroid, prostate, lung, colorectal, pancreatic, and breast cancers, suggesting that LSD1 can be developed as a molecular target for cancer $[111,112]$. Instead of directly promoting the transcriptional activity of HIF, LSD1 has been reported to regulate the ubiquitin-degradation pathway of its protein, thereby affecting its activity [112]. In papillary thyroid carcinoma (PTC) tissues, high expression of LSD1 stabilizes HIF- $1 \alpha$ to avoid its proteasomal degradation, and database prediction shows that HIF- $1 \alpha$ is enriched near the miR-146a promoter region [112]. In vitro experiments, HIF- $1 \alpha$ increased the expression level of miR-146a, and upregulated miR-146a inhibited the expression of target gene GABPA, finally leading to further malignant transformation of PTC [112]. The nude mouse model also further verified that LSD1 could upregulate the expression of miR-146a [112]. LSD1 also has the function of non-histone lysine methylation [113], which is not discussed here. In addition, many recent studies have shown that LSD1 can be an important molecular target for the treatment of acute myeloid leukemia [114, 115], but therapies directly associated with HIFs activity need to be further explored.

\section{Histone acetylation and deacetylation are associated with HIF-a activity} p300/CBP and TAT-interactive protein 60 (TIP60) have acetylase activities that affect the transcriptional activity of HIF-1 $\alpha$, while HDAC4- 6 in histone deacetylases (HDACs) regulate the stability of HIF-1 $\alpha$ [2, $116,117]$. p300 and cyclic AMP response elementbinding protein $(\mathrm{CBP})$ are transcriptional coactivators with strong histone acetylase activity, which can regulate chromatin structure and make it more accessible to epigenetic regulators $[118,119]$. p300 and CBP are tumor suppressor genes, and their mutations are involved in a variety of cancer pathways, affecting the development of tumors [118, 120, 121]. They bind to transcriptional activation regions of HIF- $1 \alpha$ and HIF$2 \alpha$ genes, and acetylase activity of the p300/CBP complex, along with other deacetylases, is responsible for $70 \%$ target genes activation of the HIF pathway downstream [122]. Under nomorxia, FIH-mediated hydroxylation of an asparaginyl residue inhibited HIF- $\alpha$ recruitment of $\mathrm{p} 300 / \mathrm{CBP}$, thus affecting the further activation of the HIF pathway [123]. The acetylation of HIF-1 $\alpha$ at lysine 709 by p300 increases the stability of HIF proteins, and SIRT1 deacetylates the p300 /CBP-associated factor (PCAF)-mediated lysine acetylation state of HIF- $1 \alpha$ at lysine 674 to prevent p300/CBP recruitment and hypoxic-induced gene activation $[124,125]$. And several studies have shown that inhibiting the functional activity of p300/CBP with inhibitors can be a potential target for tumor therapy $[121,123,126]$. TIP60 is a histone lysine acetylase that is involved in oncogenic pathways and affects the development and progression of tumors in a variety of ways [127]. TIP60 acts as a transcriptional coactivator of HIF-1 $\alpha$, affecting chromatin structure and regulating HIF target genes in colorectal cancer [128-130]. HIF-1 $\alpha$ interacts with the component of the TIP60 complex, promoting TIP60 recruitment to chromatin (Fig. 1b) [128]. HIF-1 $\alpha$ acts on TIP60, which leads to chromatin histone acetylation and then to the activation of polymerase II, which ultimately activates HIF- $1 \alpha$ target genes transcription [128]. This suggests that TIP60 acts as a mediator, linking HIF$1 \alpha$ to HIF- $1 \alpha$ target genes. In human cells, the 18 deacetylases are divided into four classes [131]. The class II is divided into two subclasses, IIa (HDAC4, HDAC5, HDAC7 and HDAC9) and IIb (HDAC6 and HDAC10), among which HDAC4, HDAC5 and HDAC6 are thought to be related to the regulation of HIF functional activity $[2,131,132]$. Within VHLpositive cancer cell lines, HDAC4 inhibition by shRNA increases HIF- $1 \alpha$ protein acetylation levels, while HDAC4 overexpression decreases HIF- $1 \alpha$ acetylation levels [133]. More, stable inhibition of HDAC4 in VHL-positive cells can not only reduce the transcriptional activity of HIF-1 and the expression of HIF-1 target genes, but also reduce the level of glycolysis [133]. Nucleus accumbens-associated protein-1 (NAC1), a member of the BTB/POZ gene family, can also interact with HDAC4 [134]. Intracellular accumulation of HDAC4 leads to reduced acetylation of HIF-1, but NAC1 binding to HDAC4 inhibits phosphorylation of HDAC4 at serine 246 and prevents nuclear export that leads to cytoplasmic degradation of HDAC [134]. In this context, the transcriptional activity and stability of HIF- $1 \alpha$ was enhanced via NAC1-HDAC4-HIF-1 $\alpha$ pathway [134]. HDAC5 has been found to promote transcriptional activation of HIF- $1 \alpha$ and nuclear accumulation of HIF-1 $\alpha$ [135]. The molecular chaperone Hsp70 acts as a substrate for HDAC5, and its deacetylation mediated by HDAC5 promotes the interaction of HIF-1 with Hsp90 [135]. HDAC6 plays an important role in hypoxic-induced reactions [136, 137]. HDAC6 is significantly down-regulated in liver cancer tissues, and low expression of HDAC6 is closely associated with poor prognosis [137]. HDAC6 promotes cell proliferation of hepatocellular carcinoma and HIF- $1 \alpha$ and VEGFA expression, thereby promoting HIF-1- 
mediated angiogenesis in hypoxic conditions [137]. Multiple HDACs inhibitors can reverse the stabilization of HIF by HDACs, suggesting that HDACs, and specifically HDAC4-6, may be a molecular target for cancer therapy [138-141].

\section{Non-histone lysine acetylation is associated with HIF-a activity}

HIF- $\alpha$ activity is also regulated by protein acetylation. For instance, lysine residue 532 (Lys-532) and lysine residue 709 (Lys-709) of HIF-1 $\alpha$ protein can be acetylated in cancer cells $[125,142]$. Arrest-defective protein 1 (ARD1) is functionally active as both $\mathrm{N}$-terminal $\alpha$ protein and $\varepsilon$-protein acetyltransferase activities in yeast, and was reported to be overexpressed in lung cancer, breast cancer, colorectal cancer and hepatocellular cancer [142, 143]. The lysine 532 of HIF is acetylated by ARD1, making HIF-1 more likely to interact with VHL for degradation [144]. Although ARD1 transcripts and proteins do decrease in hypoxic tumors, it still affects HIF- $1 \alpha$ stability [142]. More, lysine 709 of HIF- $1 \alpha$ is specifically acetylated by $\mathrm{p} 300$, enhancing HIF- $1 \alpha$ stability and decreasing poly-ubiquitination within hypoxic tumors [125]. And HIF-1 $\alpha$ K709A mutant protein were more stable and less p300 dependent than wild-type protein, suggesting that the interaction between HIF- $1 \alpha$ and p300 is enhanced by HIF acetylation under hypoxia [125]. NAA10 usually has no acetylase activity [145]. However, it shows $\mathrm{N}$-terminal acetylase activity similar to that of ARD1 when NAA10 is hydroxylated by $\mathrm{FIH}$ $[142,146]$. In the aerobic condition, hydroxylated NAA10 acetylates HIF- $1 \alpha$ protein and induces the protein destability [146], which suggesting that NAA10 mutation may contribute to tumor progression.

\section{Non-coding RNAs mediates epigenetic regulation on HIFs activity}

Non-coding RNAs, mainly microRNA and lncRNA, play an important role in affecting HIF activity. Some lncRNAs have gradually become important regulators in the development of hypoxic tumors [147]. In nasopharyngeal carcinoma cells (NPC), both lncRNA PVT1 and lncRNA DANCR can interact with HIF- $1 \alpha$ to influence NPC progression [148, 149]. Plasmacytoma variant translocation 1 (PVT1) is the first lncRNA gene discovered in Burkitt's lymphoma, and its lncRNA that has been reported to play a role in promoting tumor progression [147]. PVT1 activates the acetyltransferase KAT2A, and then recruits TIF1 $\beta$ to promote the transcription of NF90 [148]. This improves the stability of HIF- $1 \alpha$ protein and mRNA, and promotes further hypoxia-induced malignant phenotype of NPC [148]. Differentiation antagonizing non-protein coding RNA (DANCR) was identified as cancer-promoting gene in
NPC cells, and was responsible for poor prognosis [149]. DANCR interacts with NF90/NF45 to stabilize HIF-1 $\alpha$ mRNA and promote NPC development [149]. In breast cancer, miRNA-181c has an effect on the stability of HIF-1 $\alpha$ [150]. Nuclear factor erythroid 2-like-2 (NRF2), an important regulator of genes related to oxygen pressure, increases miR-181c level in colon cancer cells [151]. Increased miRNA-181c led to a decrease in mitochondrial oxygen consumption rate and ATP production in cancer cells with NRF2 mutation, leading to HIF- $1 \alpha$ destability [150]. It shows that down-regulation of HIF$1 \alpha$ mediated by miRNA-181c results in the inhibition of hypoxia-induced metabolic alterations within tumor cells with NRF2-silencing [150]. More, in pancreatic cancer, miRNA-646 and LncRNA-MTA2TR are also involved in the regulation of HIF- $1 \alpha$ stability, respectively, thereby affecting HIF- $1 \alpha$ accumulation in cancer cells $[152,153]$. Migration and invasion inhibitory protein (MIIP) is identified as oncogenic blocker in pancreatic cancer [152]. miRNA-646 leads to reduced stability of MIIP mRNA and inhibition of MIIP gene expression [152, 154]. HIF$1 \alpha$ indirectly inhibits MIIP expression by activating miRNA-646 transcription, however, MIIP also has the ability to reduce the activity of histone deacetylase 6 (HDAC6) and thus promote HIF-1 $\alpha$ acetylation and degradation [152]. It suggests that miRNA-646 indirectly induces HIF- $1 \alpha$ stability via HIF-1 $\alpha /$ miR-646/MIIP [152]. In addition, metastasis associated protein 2 (MTA2) is an metastasis-associated gene, and its lncRNA MTA2TR was overexpressed in gastric cancer and pancreatic cancer $[153,155]$. MTA2 has nucleosome remodeling and histone deacetylase (NuDR) complex, and thus has the function of deacetylation [156]. IncRNA MTA2TR transcriptionally elevates MTA2 expression to increase the stability of HIF-1 $\alpha$ protein through deacetylation [153].

The epigenetic regulation of these regulators on the functional activity of HIF- $\alpha$ involve the stability of HIF- $\alpha$ mRNA, the stability of HIF- $\alpha$ protein, and epigenetic reprogramming. Epigenetic factors that influence HIF- $\alpha$ stability are discussed here, but other factors that influence HIF- $\alpha$ activity, such as ATP-dependent chromatin remodelers, have been discussed in detail in other articles. Epigenetic modifications at the DNA, RNA and protein levels play an important role in HIFs availability, whether it's methylation, acetylation or their reverse reactions, understanding the accurate mechanisms may help us establish drug reaction which will be discussed below, and exploring the pathological networks that haven't found yet.

\section{Influence of intracellular metabolites on HIF-a stability through epigenetic regulation}

The stability of HIF- $\alpha$ is the basis of its activity [116]. In the previous section, we discussed a number of 
epigenetic factors affecting HIF activity in hypoxic tumors. However, metabolites produced by hypoxic tumors during metabolism also play an important role in the stability of HIF- $\alpha$ [157]. Here, the epigenetic regulation of metabolites on the stability of HIF is discussed on the basis of genetic regulation.

\section{Effects of intracellular metabolites under genetic regulation on the stability of HIF-a}

In the past few years, numerous studies have shown that metabolism is passive, subordinate to the metabolic needs of the tumor, driven by the activation of oncogenes and the inactivation of tumor suppressor factors [158]. HIF-driven tumor metabolic remodeling activates multiple metabolic pathways, including pyruvate dehydrogenase kinase 1 (PDK1), BHLH Transcription Factor (MYC), pyruvate kinase M2 (PKM2), tumor protein P53 (TP53) [159, 160]. Many HIF target genes encode special enzymes, in turn, metabolites, including succinate, fumarate, pyruvate, lactate and oxaloacetate etc. affect HIF proteins stability due to loss-of-function of PHD (Fig. 2) [161-163]. For example, three succinate dehydrogenase (SDHB, SDHC and SDHD) and fumarate hydratase are reported to response to hypoxia, and aberrant function of these enzymes inhibit the process of mitochondrial respiratory [164]. Their mutation lead to increased ROS, and altered intracellular metabolites of TCA cycle as messengers to induce HIF stability [165]. In detail, inhibition of SDH genes coding aberrant enzymes lead to the loss-of-function PHDs with increased amount of succinate. As we discussed above, PHDs are responsible for the ubiquitylation leading to degradation of HIF- $\alpha$, therefore the inhibition of PHDs leads to the accumulation PHDs substrates, above all HIF- $\alpha$ subunits [164]. Interestingly, among the accumulated substrates, succinate and fumarate could also contribute to HIF stability [165]. The recent study confirms this opinion that the FIH in concert with PHD/VHL in rapidly response to hypoxia, in turn, altered metabolites lead to HIF stability [56]. And authentic study speculated that lipopolysaccharide produced by gram-negative bacteria potently enhance the TCA-cycle intermediate metabolites succinate, performing a role of stabilizing HIF- $1 \alpha$ accompanied with increased interleukin- $1 \beta$, which finally mediating

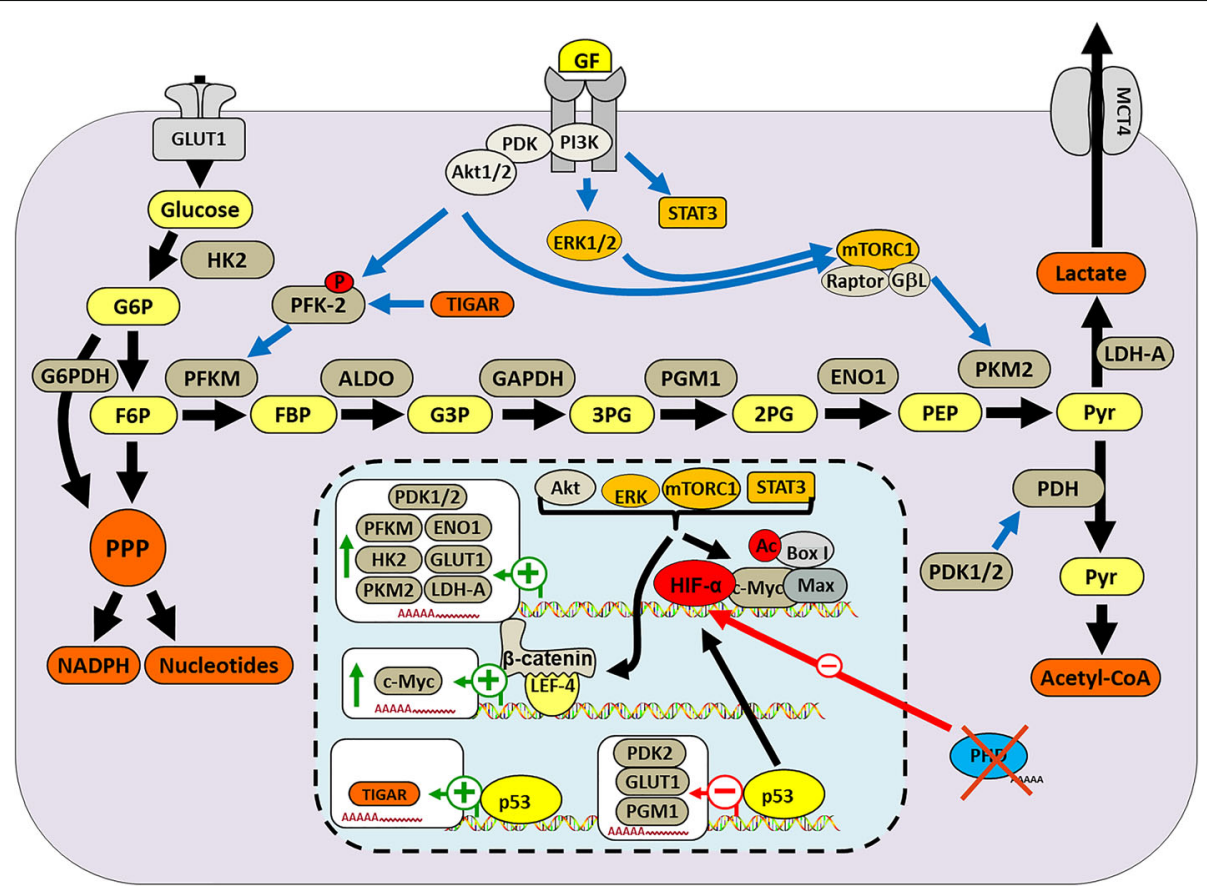

Fig. 2 Impacts of intracellular metabolites on HIF-a stability through epigenetic regulation. In hypoxic tumors, rapid proliferation requires lots of intracellular metabolites to build macromolecules, including nucleotides and proteins. Up-regulated glycolysis sustains the demands of tumor cells for intracellular metabolites. HIF target genes encoding special enzymes are activated to produce various enzymatic proteins, such as PDK1/ 2, enolase 1 (ENO1), hexokinase 2 (HK2) and so on, which leading to elevated intracellular metabolites, in turn, these metabolites including succinate, fumarate, pyruvate, lactate and oxaloacetate etc. and associated pathways involved enzymes such as PI3K, PKB, promote HIF proteins stability with PHD loss-of-function. More, p53, $\beta$-catenin and so on, could also affect HIFs stability. PFKM: phosphofructokinase, muscle; GLUT1: glucose transporter 1; PKM2: pyruvate kinase isozymes M2; LDHA: lactate dehydrogenase A; ERK: extracellular signal-regulated kinases; PGM1: phosphoglucomutase-1; G6PDH: glucose-6-phosphate dehydrogenase; Aldo: Aldosterone; MCT4: monocarboxylate transporter 4; F6P: fructose 6phosphate; FBP: fructose-1,6-bisphosphate; G3P: glycerol-3-phosphate; 3PG: 3-phosphoglyceric acid; 2PG: 3-phosphoglyceric acid; PEP: phospho enol pyruvate 
inflammation [161]. Isocitrate dehydrogenase isoform-1 (IDH1) and 2 (IDH2) mutations are considered to be associated with HIF- $\alpha$ stability in solid tumors, notably glioblastoma and acute myeloid leukemia (AML) [166, 167]. Mutant IDH proteins obtain neomorphic enzymatic activity that catalyze the transformation of $\alpha$ ketoglutarate $(\alpha-K G)$ to R-2-hydroxyglutarate (R-2HG), which activates prolyl hydroxylase domain-2 that further leads to the degradation of HIF- $\alpha$ [168]. Moreover, noncatalytic enzymes associated with metabolic plasticity could also interact with HIF- $\alpha$, such as fructose-1,6bisphosphatase (FBP1) and PKM2. In ccRCC, the loss of FBP1 has been identified, and it may function as repressor of HIF- $\alpha$ via binding to the degradation domain of HIF in the nucleus, and further inhibit ccRCC progression. In human pancreatic adenocarcinoma, high level PKM2 expression interacts with NF- $\mathrm{kB}$ and HIF- $1 \alpha$ to induce the activation of HIF target gene VEGF. In contrast to FBP1, PKM2 could function as a coactivator to directly bind with HIF- $1 \alpha$ by facilitating the recruitment of p300 [16, 37, 169].

\section{The epigenetic regulation of intratumoral metabolites on stability of HIF-a}

During tumor progression, tumor metabolism is regulated by a number of metabolic regulators, including HIF-1 $\alpha$, AMPK, mTOR, and PPAR gamma coactivator 1 alpha (PGC-1 $\alpha$ ), wherein AMPK indirectly regulates the stability of HIF-1 $\alpha$ through metabolites [170, 171]. AMPK is a heterotrimeric Ser/Thr kinase complex that acts as a cellular sensor for energy state and ROS in tumor cells to maintain intracellular energy homeostasis [170]. Acetyl-CoA is a key metabolite that links metabolism to transcription and chromatin structure [172]. AMPK regulates the levels of acetyl-CoA and $\mathrm{NAD}^{+}$to regulate the activities of histone acetylases (HATs) and HDACs, thus affecting the activity of HIF-1 $\alpha$ (Fig. 3) [173]. AMPK phosphorylates and inhibits acetyl-CoA carboxylase (ACC), thereby increasing the level of acetyl-coA in tumor cells [174]. And since acetyl-CoA is the substrate for all KATs, lysine acetyltransferase activity is increased [175]. For example, the p300/CBP family is a type of KATs whose activity can be enhanced by acetyl-CoA, which further promotes its binding to HIF$1 \alpha$ and activating most of the downstream target genes of HIF-1 $\alpha$ [121]. HDAC can be divided into four classes, among which, class I, class II, class IV are $\mathrm{Zn}^{2+}$ dependent aminohydrolases, while class III use $\mathrm{NAD}^{+}$as a cosubstrate, thereby exerting the role of deacetylase to affect the stability of HIF- $1 \alpha$ and HIF- $2 \alpha$ and thus regulate HIF-driven metabolic activities [176]. The specific mechanism by which Class III, also known as Sirtuin family, acts on HIF- $\alpha$ is discussed in the next section. In normal cells, pyruvate, as the end product of glycolysis,

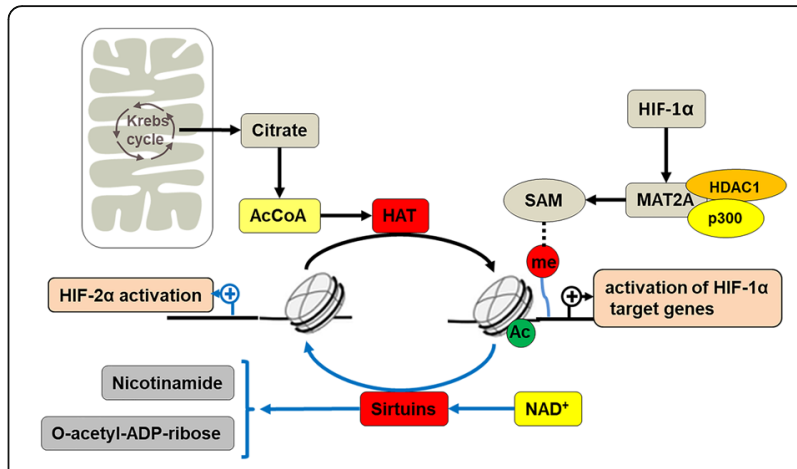

Fig. 3 The epigenetic regulation of acetyl-COA, NAD ${ }^{+}$and SAM on stability of HIF-a. In the tricarboxylic acid cycle of mitochondria, AMPK phosphorylates acetyl-CoA carboxylase (ACC), leading to increased acetyl-CoA in tumor cells. The activity of histone acetylases (HATs) such as p300/CBP, which uses acetyl-CoA as its substrate, is increased accordingly. The acetyl-CoA leads to increased p300/CBP activity, so recruitment of p300/CBP by HIF-1a results in substantial activation of HIF-1 downstream genes. In hypoxic tumors, residual Sirtuins catalyze the deacetylation of histones in $\mathrm{NAD}^{+}-$dependent reactions to produce a deacetylated substrate, o-acetyl ADP-ribose, and niacinamide. This results in changes in HIF-a and its downstream gene activation. HIF-1a recruits p300 and HDAC1 to the MAT2A promoter, leading to high expression of MAT2A. Upregulation of MAT2A regulates genomic DNA methylation status by affecting SAM levels

is decomposed by pyruvate dehydrogenase (PDH) into acetyl-CoA and $\mathrm{CO}_{2}$ in mitochondria, while generating NADH. However, in hypoxic tumor cells, HIF-1 target gene PDK1 is activated and PKD1 inactivates PDH, resulting in pyruvate being excluded from mitochondria [27]. Finally, the levels of acetyl-CoA and $\mathrm{NAD}^{+}$in hypoxic tumors were reduced, which seemed to contradict their ability to stabilize HIF- $1 \alpha$ and HIF- $2 \alpha$ and promote tumor progression $[177,178]$. However, pyruvate fails to enter the electron transport chain, which reduces oxidative phosphorylation levels and ROS production [178, 179]. ROS can promote death of tumor cells through many pathways, such as ferroptosis [46, 180, 181]. Therefore, compared with cell death caused by ROS, tumors prefer to choose other conventional metabolites, such as succinate, glutamate and fumarate, to maintain tumor progression [157].

The production of SAM also plays an important role in DNA methylation in tumor metabolic fitness and plasticity $[27,182]$. SAM can be synthesized from methionine and ATP catalyzed by methionine adenosyltransferases (MATs), and is involved in the regulation of genomic DNA methylation status [75, 183]. For instance, SAM metabolism affects DNA methylation status and lead to metabolic reprogramming in liver cancer progression and prognosis [184]. Down-regulation of the liver-specific MAT1A gene encoding isozymes MATI/III and up-regulation of the MAT2A gene encoding 
isozyme MATII occur in hepatocellular carcinoma, and the resulting MAT1A: MAT2A switch leads to a decrease in SAM level [184, 185]. However, studies showed that the MAT1A: MAT2A switch and low SAM level are associated with $\mathrm{CpG}$ sites methylation of MAT1A and MAT2A promoters in HCC [186]. With the involvement of HIF-1 $\alpha$, SAM affects the activity of ERK $1 / 2$ by interfering with DUSP1 [187]. As a member of the AMPK family, active ERK1/2 phosphorylates serine residue of DUSP1, leading to DUSP1 ubiquitylation and degradation [187]. However, SAM treatment stabilizes USP1 at both mRNA and protein levels, suggesting that AMPK is regulated by SAM [188]. Interestingly, HIF- $1 \alpha$ stabilizes the ERK1/2 target gene FOXM1 and mediates metabolic reprogramming regulated by AMPK under hypoxia in HCC [189]. Hypoxia decreases SAM levels in HCC cells, leading to reduced genomic DNA methylation levels [190]. Mechanistically, hypoxia-induced HIF$1 \alpha$ recruits p300 and HDAC1 to the promoter of MAT2A, and the resulting up-regulation of MAT2A plays an important role in decreasing SAM level with specific mechanism (Fig. 3) [190]. In addition, reliable studies have shown that MAT2B, an important regulator of MAT2A, inhibits the activity of MAT2A at high SAM levels, and acts as a co-activator of MAT2A at low SAM levels [191]. These results suggest that high expression of MAT2A, which is activated by HIF-1 $\alpha$ in hypoxia, can be negatively regulated by MAT2B, resulting in the decrease of SAM instead [191]. This further suggests that in hypoxic tumors, SAM biosynthesis may affect HIF$1 \alpha$ activity by regulating genomic DNA methylation status.

In general, there are many factors affecting the stability and activity of HIF- $\alpha$, and metabolites are one of the most important aspects, which is why we discuss it separately. In terms of genetic regulation, the effect of intracellular metabolism on HIF- $\alpha$ is usually involved in metabolic reprogramming, especially glucose metabolism, but evidence on the epigenetic regulation of HIF- $\alpha$ activity by metabolites is limited.

\section{Role of HIF-a in nutrient deprivation during cancer progression through epigenetic regulation} The hypoxic tumors are characterized by oxygen deficiency and nutrient deprivation, which mainly involves glucose and amino acids [192, 193]. Growing evidence have shown that tumors prefer glycolysis, even in aerobic conditions [14]. Histone deacetylases and non-coding RNAs both play important roles in HIF-involved glucose depletion [194, 195]. In addition, fatty acid metabolism also constitute an important part of tumor metabolic reprogramming [196]. Here, we briefly reviewed not only HIFmediated genetic regulation of tumor metabolism, but also epigenetic regulation of glucose deprivation. Here, we briefly review the overall glucose metabolism of tumors by genetic regulation, and try to discuss epigenetic regulation of glucose metabolism.

\section{Metabolic reprogramming with canonical genetic regulation}

The patterns of tumor metabolism are very different from those of surrounding tissue [14]. Only $10 \%$ of ATP in normal tissues comes from glycolysis, and the rest $90 \%$ comes from metabolic activities in mitochondria [157]. However, 50\% of ATP needed by tumors comes from glycolysis and mitochondria, respectively [157]. HIF-dependent glycolysis is a linear metabolite processing process involving the expression of several genes, including glucose transporter (GLUT) genes, enzyme genes that break down glucose into pyruvate, and enzyme genes that clear pyruvate [197]. HIF-1 increases the rate of glucose internalization by activating the expression of GLUT1 and GLUT3 [198, 199]. Increased GLUT1 and GLUT3, induced by HIF-1, transport glucose from high concentration to low concentration into tumor cells, and glucose entering the cells can be used for multiple purposes, including glycogen synthesis, protein modification, and pentose shunt [157]. In the cytoplasm, hexokinase (HK) converts glucose to glucose 6phosphate (G6P), which is then converted to glucose 1-phosphate (G1P) by phosphoglucomutase 1 (PGM1) [200]. G1P can be further transformed into UDPglucose to form the constituent unit of glycogen. When glycogen is decomposed in the cytoplasm, G1P can be regenerated due to the functions of glycogen phosphorylase (PYG) and a debranching enzyme [200]. And G1P can be converted by PGM1 into G6P to participate in glycolysis [200]. Studies have shown that epithelial cells store energy in the form of glycogen, but glycogen is not a major source of energy for tumors [201]. In addition to glycogen metabolism, the main fate of glucose is the synthesis of pyruvates under the activities of the 6-phosphofructo-2-kinase/ fructose-2,6-bisphosphatase (PFKFB) enzymes induced by HIF-1 [157]. That is, glucose, $2 \mathrm{ADP}$ and $2 \mathrm{NAD}^{+}$ are converted into 2 pyruvates, $2 \mathrm{ATP}$ and $2 \mathrm{NADH}$ during glycolysis [157]. In most hypoxic tumors, pyruvate, the end product of glycolysis, is the primary carbon source, and HIF-1-induced pyruvate dehydrogenase kinase 1 (PDK1) is a protein kinase that phosphorylates and inactivates the mitochondrial enzyme pyruvate dehydrogenase (PDH) responsible for pyruvate catalysis [202]. PDH catalyzes pyruvate into acetyl-CoA and $\mathrm{CO}_{2}$ in mitochondria to produce $\mathrm{NADH}$, but with the inactivation of $\mathrm{PDH}$, this process is blocked [203, 204]. 
Fatty acid metabolism also exist in tumor cells, promoting tumor progression. It is important for tumors to reverse or mitigate the adverse effects of nutrient deprivation because the cells at the core site are highly plastic and contribute to tumor progression [27, 205]. Thus, HIF activates a series of enzymatic genes that perform metabolic reprogramming through the fatty acid (FA) synthase system [165, 206, 207]. For example, the transcriptional activity of genes coding fatty acid synthases, particularly fatty acid synthase (FASN) and acetyl-CoA carboxylase (ACC), leas to elevated de novo FA synthesis [208]. HIF-1 $\alpha$ not only inhibits pyruvate metabolic pathway in mitochondria during glycolysis, but also inhibits fatty acid oxidation (FAO) to promote tumor progression (Fig. 4) [209-211]. Mechanistically, two FAO enzymes, medium-chain acyl-CoA dehydrogenase (MCAD) and long-chain acyl-CoA dehydrogenase (LCAD), reduce ROS levels to promote tumor cell proliferation, and loss-of-function of LCAD further accelerates cancer progression via involving in phosphatase and tensin homolog (PTEN) pathway [209]. In addition, HIF- $2 \alpha$ has been found to be highly expressed in patients with liver disease, and with the activation of its target genes, such as SRT1 and AMPK, liver fibrosis is intensified, suggesting that HIF-2 inactivation can reverse the progression of liver cancer [212, 213]. In the case of tumor nutritional deprivation, fatty acid metabolism regulated by HIF- $1 \alpha$ and HIF- $2 \alpha$ have gradually shown its importance, but more work, such as epigenetic regulation, still needs to be further studied.

\section{The histone deacetylases regulate glucose metabolism in tumors via epigenetic regulation}

Limited literature suggests that histone deacetylases, especially members of the Sirtuin (SIRT) family, play an important epigenetic role in HIF-regulated glucose metabolism [195, 214]. SIRT family can be divided into four classes, SIRT1, SIRT2 and SIRT3 belong to class I, SIRT4 belong to class II, SIRT5 belong to class III, and SIRT6 and SIRT7 belong to class IV [215]. Among them, SIRT1, SIRT3, SIRT6 can play regulatory roles in multiple links of glucose metabolism regulated by HIFs [195, 216]. Under nomorxia, SIRT1 promotes HIF- $1 \alpha$ degradation by stabilizing intracellular VHL transcripts, and SIRT1 can further deacetylate HIF- $1 \alpha$ in the nucleus, affecting the interaction between HIF- $1 \alpha$ and p300 to affect the activation of a range of metabolism-related target genes [124]. In hypoxic tumors, the activity of SIRT1 is inhibited by the decreasing $\mathrm{NAD}^{+}$, but residual SIRT1 deacetylates HIF- $2 \alpha$ and activate HIF- $2 \alpha$ [217]. Therefore, it suggests that SIRT1 may form a dynamically balanced pool in hypoxic tumor cells, regulating the activities of HIF- $1 \alpha$ and HIF- $2 \alpha$ according to the

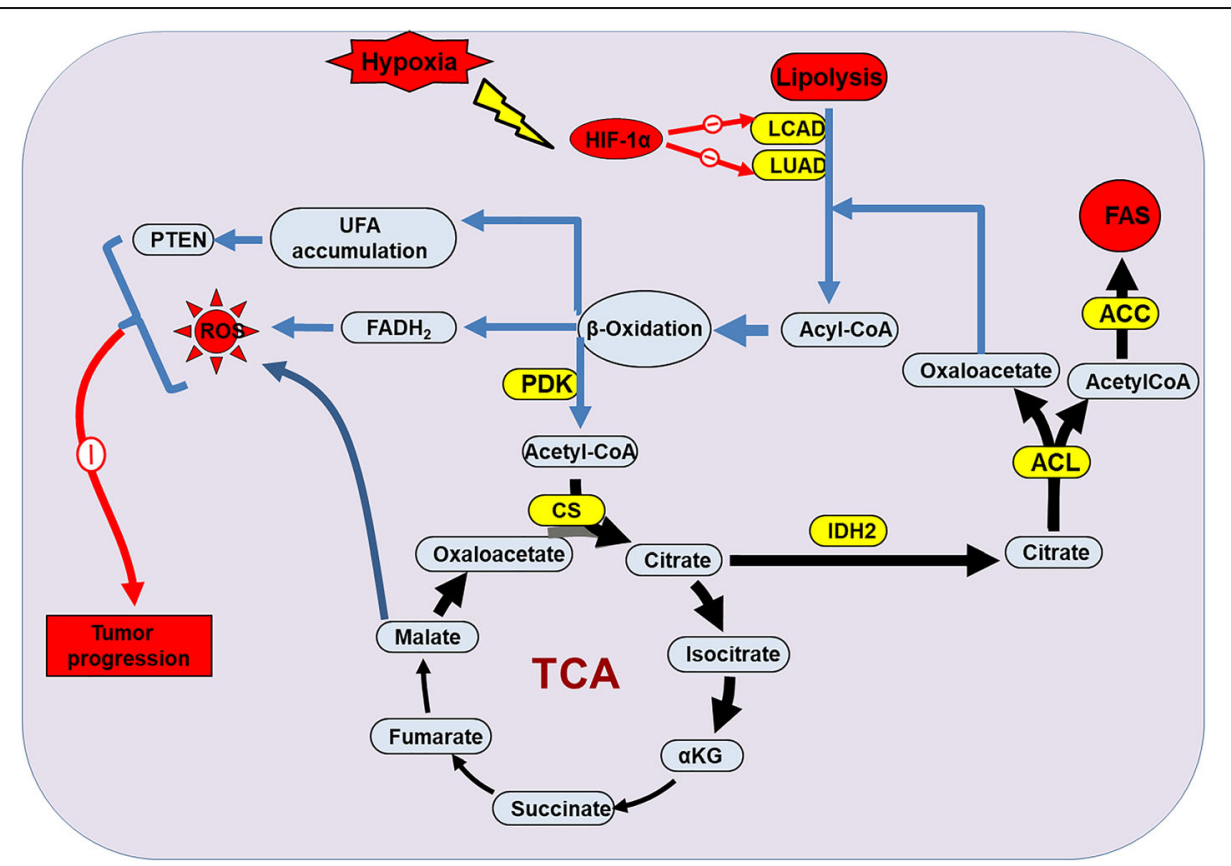

Fig. 4 Role of HIF-a on fatty acids metabolism during cancer progression via epigenetic regulation. Two FAO enzymes, the acyl-CoA dehydrogenases MCAD and LCAD, are inhibited by the activated HIF-1a under hipoxia. LCAD and MCAD loss disturbs the process of FAO which leads to ROS alteration via TCA (tricarboxylic acid) cycle and separate LCAD loss inhibits PTEN pathway, which finally mediate resistance to tumor progression. HIF-1a loss-of-function may rescues the resistance and contributes to cancer progression. CS: citrate synthase; ACL: acetonecyanohydrin lyase; ACC: acetyl-CoA carboxylase alpha 
oxygen availability [195, 218]. In tumor cells, SIRT3, as the major mitochondrial deacetylase in the Sirtuin family, promotes mitochondrial respiration and inhibits HIF-regulated glycolysis [219]. SIRT3 can deacetylate and activate various mitochondrial metabolic enzymes involved in TCA and FAO enzymes, including LCAD, 3-hydroxy-3-methylglutaryl CoA synthase 2 (HMGCS2), isocitrate dehydrogenase 2 (IDH2) and glutamate dehydrogenase (GDH) to block the supply of glycolysis to the tumor cells [219]. SIRT6defiencicy mice showed fatal hypoglycemia, suggesting that SIRT6 is involved in glucose metabolism [220]. SIRT6, an H3K9 deacetylase, inhibits transcriptional activation of HIF- $1 \alpha$ in non-tumor cells and reduces the level of glucose metabolism, but SIRT6 knockdown increased glucose uptake in mice, inhibited mitochondrial respiration, and effectively responded to nutrient deprivation [220]. However, in tumor cells such as colon cancer cells, SIRT6 binds directly to the hypoxia-responsive elements of the glycometabolism genes and blocks HIF- $1 \alpha$-induced glycometabolism without activating oncogenic pathway [219]. This suggests that SIRT6 acts as a tumor suppressor in the development of tumors by inhibiting glucose metabolism [219]. Other members of the Sirtuin family, such as SIRT7, have also been shown to influence HIFinduced metabolic activity via decreasing HIF- $1 \alpha$ and HIF- $2 \alpha$, but the specific mechanism remains to be investigated [221].

\section{The role of non-coding RNAs in glucose metabolism via epigenetic regulation}

There is considerable evidence that non-coding RNAs, including microRNAs and lncRNAs, regulates HIFinduced metabolic activity $[194,222]$. In liver cancer, miR-3662 can inhibit the growth and proliferation of liver cancer cells by negatively regulating HIF- $1 \alpha-$ mediated glycolysis [223]. miR-3662 is low expressed in liver cancer tissues, and this low expression is closely related to tumor size, multiplicity and metastasis [223]. Mechanistically, miR-3662 down-regulates HIF- $1 \alpha$ expression, thereby reducing lactate level, glucose metabolism rate, intracellular glucose-6-phosphate content, ATP level, but increasing oxygen consumption rate, suggesting that miR-3662/HIF- $1 \alpha$ axis is closely related to glucose metabolism reprogramming [223]. In colorectal cancer cells, miR-23a, miR-27a and miR-24 were found to be upregulated microRNAs that collectively regulate the glucose metabolic network [224]. HIF-1 $\alpha$ binds to the promoter of miR-23a $\sim 27 \mathrm{a} \sim 24$ cluster formed by miR-23a, miR-27a and miR-24, promoting the expression of miRNA clusters in HCC cells [224]. miR-24/ VHL/HIF- $1 \alpha$ forms a double-negative feedback regulatory pathway that can enhance the effect of HIF-1 $\alpha$ and
miR-23a $\sim 27 \mathrm{a} \sim 24$ cluster, greatly regulating the metabolic network of colorectal cancer and shifting the metabolic balance of normal cells to glycolysis [224]. Homeobox A9 (HOXA9), as the target gene of miR-365, can inhibit glycolysis by regulating HIF- $1 \alpha$ and the downstream glycolysis genes [225]. However, HOXA9 is down-regulated in cutaneous squamous cell carcinoma (cSCC), which means that the miR-365-HOXA9-HIF-1 $\alpha$ axis promotes glycolysis [225]. In chronic myelogenous leukemia (CML), curcumin was found to up-regulate the expression of miR-22 and down-regulate its target gene importin 7 (IPO7), thus affecting the nuclear transport of HIF-1 $\alpha$ [226]. Thus, the target genes of HIF- $1 \alpha$ related to glycolysis were down-regulated [226]. In acute myeloid leukemia (AML), the up-regulated expression of LncRNA urothelial carcinoma-associated 1 (LncRNAUCA1) inhibited the adriamycin (ADR)-based chemotherapy effect by negatively regulating glycolysis [227]. LncRNA-UCA1 can be directly bound to miR-125a as ceRNA, and in HL60andHL60/ADR cells, target gene hexokinase 2 (HK2) of miR-125a can be positively regulated by lncRNA-UCA1 [227]. Importantly, IncRNAUCA1 overexpression can reverse the HIF- $1 \alpha$-dependent glycolysis inhibition mediated by miR-125a in HL60andHL60/ADR cells, showing that IncRNA-UCA1 could inhibit glycolysis through miR-125a/HK2 pathway and plays an active role in overcoming chemotherapeutic resistance to AML in children [227].

Nutritional deprivation is one of the most common metabolic phenomena in hypoxic tumors, and with the involvement of the HIF family, tumors use a variety of metabolic pathways to shape the plasticity of tumor cells and their microenvironment in order to cope with or reverse undesirable situations. In terms of phenotypic plasticity, in addition to the glucose and fatty acid metabolism mentioned above, there are also amino acid metabolism that have not been discussed. However, in terms of the epigenetic regulation of HIF-related nutrient deprivation, the reference basis is still limited, mainly focusing on histone deacetylases SIRT family and noncoding RNAs. Among them, some epigenetic regulations are concentrated on HIF target genes, suggesting that seeking more downstream HIF genes may be a way to deepen our understanding of epigenetic regulation in hypoxic tumors.

\section{Role of HIF-a in tumor microenvironment through epigenetic regulation}

Many studies have shown that genetic changes fail to fully explain tumor progression, invasion and metastasis, and some epigenetic changes occurring in tumor cells have profound impacts on tumor progression [228]. Both microenvironment cues and intracellular alterations promote epigenetic regulation [228-230]. Here 
we briefly summarize the HIF- $\alpha$-related epigenetic regulation in the tumor microenvironment between tumor cells and myeloid cells.

The tumor microenvironment mainly includes inflammatory cells, accessory fibroblasts and extracellular matrix (ECM) components, which have high phenotypic plasticity [231]. Cell-to-cell contact, secretion of soluble factors and release of exosomes can lead to tumor microenvironmental disorders that have important effects on both genetic and epigenetic characteristics [232235]. Infiltrating and tissue-resident myeloid cells are important regulators of innate and adaptive immunity [236]. During inflammation, these cells can adapt to microenvironmental conditions and acquire specific functions, including phagocytosis and the production of proinflammatory cytokines [237]. This myeloid plasticity is driven in part by epigenetic regulation that maintains a stable phenotype after activation, such as demethylation by TET family member TET2 enzyme [237, 238]. There is increasing evidence that pathological activation and differentiation of myeloid cells is a marker of cancer [238]. TET2 is mutated in some malignant myelopathy, indicating its important role in the proliferation and differentiation of myeloid cells [239]. Hydroxylation of 5methylcytosine $(5 \mathrm{meC})$ was inhibited in myeloid cancer cells with TET2 mutations, which may be related to the altered methylation levels observed in these cells [240, 241]. Activation and differentiation of tolerogenic myeloid cells, including myeloid-derived suppressor cells (MDSCs), regulatory dendritic cells (regDCs) and tumor-associated macrophages (TAMs), are regulated not only by gene expression, but also by epigenetic regulation in tumor environments [235]. TET2 has been found to inhibit the expression of inflammatory cytokines IL6, which has resolved the inflammation of innate myeloid cells [242]. Interestingly, the inhibition of IL6 by TET2 requires recruitment of HDAC2 [242]. In addition, HIF- $1 \alpha$ deletion in glioblastoma cells was shown to increase TET2 transcription and translation levels and further promote ascorba-induced and TET2-dependent $5 \mathrm{hmC}$, suggesting that HIF- $1 \alpha$ is involved in regulating TET2 expression and $5 \mathrm{hmC}$ levels in malignant cells [243]. Thus, HIF- $1 \alpha$ regulation of TET2 in human metastatic melanoma can also be reflected in myeloid malignant cells. The pathological switch of immature bone marrow cells to tolerogenic MDSCs is driven by tumorderived molecules as well as epigenetic regulation [244]. MDSCs are heterogeneous populations composed of pathologically activated immature myeloid cells, which inhibit anti-tumor immune response and promote tumor angiogenesis and tumor invasion [245, 246]. In ovarian cancer, MDSCs play an inhibitory role through prostaglandin E2 (PGE2), which not only enables normal dendritic cells (DCs) to differentiate into tolerogenic
MDSCs, but also mediates MDSCs-derived PGE2 to directly inhibit $\mathrm{CD}^{+} \mathrm{T}$ cell function [235, 247]. Moreover, the generation of PGE2-mediated monocytic MDSCs is dependent on the up-regulation of DNA methyltransferase 3A (DNMT3A) [248]. In MDSCs, the upregulation of DNMT3A in is accompanied by specific DNA methylation and immunogenic-related gene suppression, while the downregulation of DNMT3A would lead to the decreased hypermethylation level and the loss of immunosuppressive activity of MDSCs [248]. Interestingly, primary MDSCs isolated from ovarian cancer patients showed similar hypermethylation characteristics associated with PGE2-dependent DNMT3A overexpression [248]. However, DNMT3A was found to methylate and inactivate the HIF- $2 \alpha$ gene EPAS1, and inactivation of DNMT3A in the early stages of tumor cell progression leads to abnormal activation of EPAS1 [249]. This allows cancer cells to take advantage of the HIF- $2 \alpha$ pathway in the hypoxic tumor microenvironment to form a cell mass larger than the oxygen diffusion limit [249].

As an important component of the microenvironment, stromal cells also have close epigenetic links with tumor cells [250, 251]. For example, histone methyltransferase enhancer of zeste homolog 2 (EZH2) regulates its target gene HIF- $1 \alpha$ to influence the status of the tumor microenvironment [252]. The specific mechanism will be discussed in other sections. However, the involvement of HIF- $\alpha$ in the epigenetic mechanisms between immune cells and tumor cells remain unclear. The reason for this phenomenon may be that the tumor microenvironment is a complex system, and a lot of epigenetic regulation in tumor progression will affect the microenvironment and tumor cells plasticity, so HIF- $\alpha$ may not be the only participant in such a complex epigenetic regulatory network.

\section{Role of HIF-a on extracellular matrix remodeling through epigenetic regulation}

The extracellular matrix (ECM) is a dynamic, noncellular and three-dimensional structure that occurs in all tissues [253]. ECM is composed of collagen, elastin fibrils, proteoglycan, glycosaminoglycan, glycoprotein and protease, which are interconnected to form a dynamic cell regulatory niche and provide structural stability [254]. Studies have shown that ECM is sustainably remodeled to play an important role in the proliferation, migration, adhesion, invasion and metastasis of tumor cells $[255,256]$. In intratumoral hypoxia, HIF-1 $\alpha$ activates genes encoding collagen prolyl hydroxylases, such as P4HA1 and P4HA2, and collagen prolyl hydroxylases, such as PLOD2 [257]. In this context, epigenetic regulation mainly involves non-coding RNAs [258].

VEGF is an important factor in the regulation of tumor angiogenesis [259]. Hypoxia is a major regulator 
of VEGF expression via HIFs [260]. HIFs and its target genes such as epidermal growth factor and plateletderived growth factor coordinate VEGF expression within tumor cells $[260,261]$. Studies have shown that miRNAs targeting the HIF-VEGF axis may have important effects on angiogenesis [258, 262]. For example, miR-484 works by targeting VEGFB and VEGFR2 pathways to determine chemotherapy resistance in serous ovarian cancer [262]. In addition, miR-120 is considered to be the most important miRNA induced in epithelial cells [263]. miR-210 is overexpressed in normoxic epithelial cells, which stimulates the formation of capillarylike structures and promotes VEGF-driven cell migration [264]. However, hypoxia-induced mir-210 blockade could inhibit the above phenomena, because during HIF-induced hypoxia, mir-210 directly down-regulated its target gene tyrosine kinase ligand Ephrin-A3 to eventually inhibit the survival, migration and differentiation of the endothelial cells [264]. In this case, VEGFmediated angiogenesis is blocked in hypoxia, which may be further hypothesized to be the same in epithelial tumors [265]. ECM plays a fundamental role in controlling angiogenesis by providing basic structural support for cytokines, direct signal transduction function, and scaffolding $[259,266]$. Thus, ECM has long been considered essential for all stages of angiogenesis [267]. However, a recent study has shown that VEGF also plays an important role in ECM remodeling in metastatic colorectal cancer (mCRC) [268]. In patients with mCRC who were treated with bevacizumab prior to surgical intervention, deposits of hyaluronic acid (HA) within the tumor were found [268]. At the same time, anti-VEGF therapy was found in the homologous mCRC mouse model to significantly increase the expression of $\mathrm{HA}$ and sulfated glycosaminoglycans (sGAGs), but not significantly change collagen deposition, indicating that tumor hypoxia induced by treatment promotes ECM remodeling [268]. However, we do not know exactly which HIF- $\alpha$ is involved in regulating hypoxic activity in this study, and further investigation is needed.

There are many factors that regulate ECM remodeling, but miRNA is undoubtedly an important link. The regulation of miRNA on ECM remodeling mainly focuses on VEGF. Whether other enzyme genes involved in ECM remodeling also generally accept the regulation of miRNA or even other non-coding RNAs has not yet formed an understanding paradigm.

\section{Role of HIF- $a$ in metastasis through epigenetic regulation}

Tumor metastasis is a major challenge in clinical management and is often associated with high mortality from cancer because it cannot be cured with conventional chemotherapy and radiotherapy [269]. Metastasis is a complex dynamic process in which highly aggressive tumor cells acquire the ability to spread from the primary site to new tissues and organs and eventually survive at distant sites [270]. Hypoxia has become a key microenvironmental factor regulating metastasis, especially HIF signaling pathway [271]. From a genetic point of view, metastasis may result from a succession of genetic mutations [272]. Therefore, for a long time, the use of sequencing technology to analyze the mutation profiles on a genome-wide scale has been a hot topic [272] However, in recent years, it has been suggested that traditional mutation drivers cannot explain the phenomena observed in experiments or clinical practice, so it has been suggested that epigenetic regulation may play an extremely important role, especially in hypoxia-linked metastasis [271].

Activation of HIF signaling regulates multiple stages in the cascade of metastasis, including invasion and migration, intravasation and extravasation, establishment of the pre-metastatic niche, and survival and growth at distant organ sites [269]. Epigenetic regulation of gene expression profiles usually affects metastasis in three ways: (1) regulation of key genes involved in metastasis; (2) extensive epigenetic remodeling due to changes in cell state; and (3) epigenetic regulation of non-coding RNA in tumor metastasis [272-276]. In the first way, epigenetic regulators of HIF are JMJD2C, TET1 and VHL [99, 277-279]. JMJD2C specifically interacts with HIF-1 $\alpha$, and HIF- $1 \alpha$ can recruit JMJD2C into the hypoxia response elements of HIF-1 target genes [277]. JMJD2C reduces the level of trimethylation on the histone $\mathrm{H} 3$ at lysine 9 (H3K9), and activate the genes lysyl oxidase-like protein 2 (LOXL2) and L1 cell adhesion molecule (L1CAM) that can promote lung cancer metastasis [277]. TET1, as DNA demethylase, is thought to be related to tumor metastasis [280]. TET1, as DNA demethylase, is thought to be associated with tumor metastasis, and hypoxia increases the expression of TET1 in a HIF-1 $\alpha$-dependent manner [281, 282]. Because the binding of HIF- $1 \alpha$ to HRE of target genes depends on the methylation level of CpG, TET1 can regulate the HIF- $1 \alpha$ target genes by regulating the methylation state of HRE [278]. Moreover, TET1 E2082K mutant inhibits the TET1-enhanced cell migration in colon cancer [278]. VHL regulates hypoxic signaling by controlling the ubiquitination and degradation of HIF- $\alpha$ protein, thus genetic or epigenetic inactivation of VHL leads to constitutive activation of HIF- $1 \alpha$ and HIF-2 $\alpha$ [283]. Epigenetic modification of prometastatic genes in VHLdeficient ccRCCs cell subsets was found to increase the expression of metastasis-related HIF target genes [284]. For example, studies on two important pro-metastatic genes chemokine (C-X-C motif) receptor 4 (CXCR4) and cytohesin 1 interacting protein (CYTIP) have found 
that ablation of the polycomb repressive complex 2 (PRC2)-dependent histone H3 lysine 27 trimethylation activates the expression of HIF-driven CXCR4 [283]. To promote chemotactic cell invasion, DNA methylation is lost, leading to HIFF-driven CYTIP gene expression to protect tumor cells from death chemical signals [283]. In the second way, epithelial-mesenchymal transition is a beautiful example [274]. EMT is a key process in tumor metastasis, that is, the transformation of welldifferentiated epithelial cells into less differentiated mesenchymal cells makes it easier for tumors to invade adjacent tissues and spread to distant organs for survive $[274,285]$. EMT induced by hypoxic signaling can be regulated by HDAC3 and WD repeat containing protein 5 (WDR5) to regulate the inhibition of epithelial genes and the activation of mesenchymal genes [286]. In hypoxia, HDAC3 and WDR5 are activated by HIF- $1 \alpha$ to recruit histone methyltransferase (HMT) complexes to increase histone $\mathrm{H} 3$ lysine 4-specific HMT activity and promote the expression of mesenchymal genes [286]. In addition, HDAC3 also acts as a cofactor to inhibit epithelial gene expression, and WDR5 knockout can eliminate mesenchymal gene activation [286]. This suggests that HDAC and WDR5 can jointly epigenetically regulate the metastatic phenotype of cancer under the regulation of HIF-1 $\alpha$ [286]. For the third way, both lncRNA and miRNA can interact with HIF respectively or jointly to regulate tumor metastasis $[149,287,288]$. For example, the taurine upregulated gene 1 (TUG1), as a potential oncogene, has been found to be abnormally expressed in osteosarcoma (OS) and has been associated with distant metastasis [288]. TUC1 expression was significantly increased in OS tissues [288]. TGF- $\beta$ from cancer-associated fibroblasts (CAFs) can up-regulate the expression of TUG1, and the crosstalk between CAFs and OS activate TUG1 to generate lncRNA TUG1 and promote the metastasis of OS [288]. The specific expression of TUG1 competitively keep HIF-1 $\alpha$ mRNA 3'UTR from miR-143-5p [288]. In addition, in hepatocellular carcinoma, lnc RNA ubiquitin conjugated enzyme E2C pseudogene 3 (UBE2CP3) has been reported as an oncogene that promotes tumor metastasis [289]. UBE2CP3, which is highly expressed in hepatocellular carcinoma tissues, promotes human umbilical vein endothelial cell (HUVEC) proliferation, migration, and tube formation through the ERK/HIF-1/p70S6K/VEGFA axis in vitro and in vivo compared to paracancer tissues, leading to upregulation of VEGFA expression [289]. Recent studies have shown that methylation leads to miRNA silencing and that these silenced miRNAs are reactivated by demethylation [275, 276, 290]. The re-expression of these silenced miRNA can regulate the tumor microenvironment and promote tumor metastasis [291]. This suggests that global hypomethylation is a feature of cancer cells, and that the crosstalk between HIF- $\alpha$ and miRNA may also involve methylation changes [291].

Tumor metastasis is often associated with poor prognosis and can be regulated by both HIF- $\alpha$ and epigenetics. Although disordered epigenetic patterns in cancer cells have long been identified, they have for a long time been ignored. But with the discovery of promoter hypermethylation leading to gene silencing and global hypomethylation in cancer cells, we have gained a deeper understanding of epigenetic disorders involved in HIF- $\alpha$ in cancer cells. However, many epigenetic mechanisms do not directly regulate HIF- $\alpha$ or are directly regulated by HIF- $\alpha$, suggesting that these mechanisms are complex and that other intermedi are involved, which need to be further explored.

\section{Hypoxia and targeted therapy via epigenetic interference}

Given the association between hypoxia and chemoresistance, radioresistance and targeted therapies, hypoxia has been regarded as a therapeutic target, and epigenetic therapies, particularly anti-angiogenic treatment, VHLHIF axis therapy, bromodomain extralterminal proteins (BET) inhibition and other therapies to be argued etc., are of great interests. Clinically, resistance to multitherapies has been observed, and the mechanisms behind poor outcomes vary with treatments. For example, resistance to radiotherapy is mediated by ROS which produced by ionizing radiation, however, hypoxic condition restrains the ROS production and further limits the damage to DNA. Also, chemicals can't reach the tumors in sufficient quantities due to abnormal vascularization and up-regulation of HIF signaling etc., which leads to chemoresistance [292].

\section{Anti-angiogenic therapy}

Anti-vascular therapy has long played a pivotal role in oncotherapy. Angiogenesis is a hallmark of solid tumors, and the process of which is governed by VEGF overexpression induced by hypoxia [293, 294]. VEGF family is composed of VEGFA, VEGFB, VEGFC, VEGFD and placenta growth factor (PlGF), which are polypeptides with homodimeric structure and are functional related. Three VEGF receptors have been indentified, including VEGFR1, VEGFR2 and VEGFR3, which are also structurally related [295]. Over-expression of VEGF family, which triggered by HIF signaling, promotes neovascularization within solid tumors and function as survival factor of neovessels to inhibit endothelial cells death to further promote angiogenesis in retina [296]. In addition, neuropilin family (NRPs) could form complex with VEGF, for example, NRP1 and NRP2 act as a coreceptor for VEGFR1/2 and VEGFR3, respectively, to regulate angiogenesis [295, 297]. Also, semaphorin (Sema) family 
and VEGF could be ligands of NRP2 receptors to regulate angiogenesis, respectively, for example, semaphorin 3A (Sema3A) interacting with NRP2 functions as a negative role in regulating physiological and pathological processes of endothelial cell. And studies indicated that Sema3A activation combines with inhibition of VEGF pathway may improve therapeutic efficacy, and thus some small-molecule tyrosine kinase inhibitors, including Axitinib, Cabozantinib, Lenvatinib and Sorafenib etc., are widely used in targeting VEGFR during clinical investigation or treatment (see review by Bedard, P. L., et al., 2020) $[298,299]$. Although inhibiting VEGF is a potent and major therapeutic strategy, more efforts need to be invested in understanding mechanisms of multikinases acting on angiogenesis to exploit more efficient anti-angiogenic therapies via epigenetic intervention [298].

\section{HIF inhibition}

Growing evidence have revealed that HIF- $1 \alpha$ and HIF$2 \alpha$ inhibitors block tumor growth through a variety of mechanisms $[18,300]$. HIF- $1 \alpha$ inhibitors have the most types, among which HDAC inhibitors are indirectly involved in epigenetic regulation [136, 301]. Studies have shown that class II HDAC is associated with the stability of HIF- $1 \alpha$ and provides a theoretical basis for targeting HIF-1 $\alpha$ with HDAC inhibitors [136]. For example, LAQ824 has been reported to promote the polyubiquitination of HIF- $1 \alpha$ by unknown mechanisms, thereby inhibiting the function of HIF- $\alpha$ [136]. Due to HIF- $1 \alpha$ inhibition, the regulation of HIF- $1 \alpha$ by class III HDAC is blocked, thus indirectly blocking the epigenetic regulation of HIF- $1 \alpha$ by class III HDAC [176]. In addition, HIF- $2 \alpha$ inhibitors, including PT2385 and Vorinostat, inhibit the HIF pathway by interfering with epigenetic mechanisms [302, 303]. Clinically, adjuvant retinoic acid (RA) therapy has a poor response to high-risk neuroblastoma [303]. However, study has shown that 5-Azadeoxycytidine (AZA) as a DNA-demethylating agent increases the sensitivity of high-risk neuroblastoma to RA, and AZA and RA combined therapy inhibits the growth of high-risk neuroblastoma. This combined treatment induces high levels of transcriptional responses regulated by HIF-2 $\alpha$ [303]. After treatment with HIF- $2 \alpha$ inhibitor PT2385, the sensitivity of tumor cells to AZA and RA combined therapy decreased, suggesting that HIF- $2 \alpha$ is a tumor suppressor in neuroblastoma [303]. In fact, PT2385 indirectly affects DNA methylation involving AZA by inhibiting HIF-2 $\alpha$. More, studies have shown that the expression level of HIF-2 $\alpha$ gene EPAS1 in human soft tissue sarcomas (STS) is lower than that of the corresponding normal tissue [302]. Vorinostat, a clinically approved HDAC inhibitor, promotes HIF- $2 \alpha$ accumulation, leading to increased tumor growth, which is reversed by HIF-2 $\alpha$ deletion [302]. This indicated that Vorinostat mainly affected the transcriptional activity of HIF-2 $\alpha$ [302]. These are not the only drugs that target HIF- $1 \alpha$ and HIF- $2 \alpha$. These drugs are of great interest in their own right and cannot be ignored.

\section{Targeting VHL loss for cancer treatment}

VHL loss is linked with HIFs over-expression within tumors, especially ccRCC, which observed in clinical trials, and thus small molecule inhibitors that target VHL are widely used in clinical studies [304, 305]. VHL as a tumor suppressor mediates many cellular processes due to its multi-functional role, in which interacted with HIF signaling is the most notably physiological event that VHL binds to Elongin B, Elongin C, Cul2, and Rbx1 proteins forming E3 ligase, leading to HIF- $\alpha$ degradation inhibiting tumor progression [306]. For a long period, the main direction of ccRCC treatment is understanding mechanisms that VHL loss drives tumorigenesis, especially downstream of VHL-HIF pathway, including glutamine metabolic genes, mTOR signaling and lipid metabolism, among others [210]. Glutamine is transformed into glutamate which is subsequently catalyzed into 2-oxo-glutarate (2-OG), and further into lipid via glutaminase enzymatic function in VHL-loss tumor cells. Inhibiting glutaminase blocks the conversion from glutamine to substrates associated with HIF signaling, which may serves as potential therapeutic target [307]. More, mutations in mTOR interdict the PI3K-AKTmTOR pathway, for example, mutations in PTEN lipid phosphatase and the Tuberous Sclerosis Complex 1/2 (TSC1/2) leads to mTOR dysfunction, which resulting in usage of mTOR inhibitors in clinical treatment [298]. Authentic study noted that VHL-deficient germline resulting in reduced high-density lipoprotein (HDL) cholesterol which is associated with HIF-dependent pathway, and insulin induced gene 2 (INSIG2) is subsequently activated which leads to low levels of fatty acids (FAs) and cholesterol [52]. Similarly, in tumors with VHL loss, HIF-2 $\alpha$ activation promotes lipid droplets accumulation followed by elevated expression of both FAs synthesis and FAs absorption-related genes [308]. Cutting off metabolic pathway of HIF signaling, such as lipogenic protein perilipin 2 (PLIN2) and carnitine palmitoyltransferase 1A (CPT1A), may contributes to lipid redistribution, which could be exploited as a therapeutic strategy [304, 309]. More interestingly, OTU deubiquitinase 6B (OTUD6B) as the first reported deubiquitination enzyme is capable of inhibiting pVHL ubiquitination, and the deubiquitination regulation of OTUD6B on pVHL did not depend on its enzyme activity, but via interaction with $\mathrm{pVHL}$ to enhance the stability of $\mathrm{CBC}^{\mathrm{VHL}}$ ubiquitin ligase complex, and reduce the ubiquitination degradation of $\mathrm{pVHL}$ by Trp-Asp repeat and 
suppressors of cytokine signaling box-containing protein 1 (WSB1) and E2-EPF ubiquitin carrier protein (UCP). This provides a new understanding of the mechanisms of the OTU subfamily of deubiquitination enzymes and Cullin-RING ubiquitin ligases [310].

\section{BET inhibition}

Bromodomain and extraterminal domain (BET) family proteins consists of four members, BRD2, BRD3, BRD4 and BRDT, which play an important role as epigenetic readers in gene transcriptional activation [311, 312]. The abnormal activity of the BET protein, which recognizes lysine residues of both histones and non-histones, especially BRD4, is closely associated with cancer progression, making BET a promising therapeutic target [313, 314]. The BET small molecule inhibitors can be used as a promising alternative cancer therapy [315]. Thus, BET inhibitors such as ABBV-075, ABBV-744, BAY 1238097, BMS-986158, CPI-0610, FT-1101, GS-5829, GSK2820151, GSK-525762, BI-894999, RO-6870810 and OTX-015, have been used to study their efficacy as cancer therapies in clinical trials [312]. Among them, BMS986158, OTX-015 and GSK-525762 inhibitors are three major clinical stage BET inhibitors [315].

There is limited but growing evidence that BRD4 interacts with HIFs and modulates HIF activities to develop BRD4 as a reliable therapeutic target in multiple cancers, including acute myeloid leukemia, multiple myeloma, and Burkitt's lymphoma [316, 317]. Studies on BDR4 inhibitors received rapid attention after the inhibitory effects of JQ1 and I-BET762 on BET were reported, in which JQ1 could indirectly regulate the function of HIF through BRD4 [318-320]. Within triple negative breast cancer (TNBC), JQ1 was able to alter the expression activity of $44 \%$ of the downstream genes in the HIF pathway, two-thirds of which were down-regulated including $\mathrm{CA}$, which is related to $\mathrm{pH}$ regulation, and VEGF-A, which is related to angiogenesis [318]. Although hypoxia increased the recruitment of BRD4 to CA9 and VEGF-A in tumor cells, the down-regulated CA9 and VEGF-A in tumor cells treated with JQ1 indicated that JQ1 affected the hypoxia response in which BRD4 participated [318]. Recently, Chen and Yin et al. found that NHWD-870, a novel BRD4 inhibitor, effectively inhibited the expression of BRD4 and its target gene HIF-1 $\alpha$ [315]. NHWD-870 significantly inhibits tumor growth in a variety of animal tumor models [315]. Mechanistically, NHWD-870 reduces the expression and secretion of macrophage colony stimulating factor 1 (CSF1) in tumor cells by blocking the functional activity of BRD4 and its target gene HIF-1 $\alpha$ [315]. Downregulation of CSF1 weakens the activation degree of ERK1/2 and PI3K/AKT pathways, leading to decreased proliferation and survival of tumor associated macrophages (TAMs) [315]. TAMs rely on tumorsecreted growth factors, such as CSF1, to promote tumor growth and metastasis [321]. This study revealed for the first time that the novel BET inhibitor NHWD870 , which was independently developed, can block the mechanism of tumor-macrophage interaction, providing a theoretical basis for the effective treatment for solid tumors such as melanoma by blocking the new epigenetic target BRD4 in clinical trials [315]. Studies have shown that this inhibitor increases the clinical activity by $5-50$ times compared with BMS-986158, OTX-015 and GSK525762 inhibitors, and can effectively reverse the drug resistance of tumors, which is expected to double the survival time of patients with advanced melanoma [315]. As a first class original new drug in development, NHWD-870 will be the first to carry out phase I clinical trial with melanoma in 2020 [315], which is expected to be a new broad-spectrum anticancer drug, bringing new hope for patients with advanced melanoma, small-cell lung cancer and other diseases. The evidence that BRD4 regulates the activities of HIF- $1 \alpha$ and HIF- $2 \alpha$ need to be further enriched, and targeting BRD4 is currently considered as a strategy to be developed. Together, BRD4 inhibitor exploitation plays an important potential role in cancer therapy, especially hypoxic tumors.

\section{Potential treatment based on crosstalk between HIFs signaling and ferroptosis}

Ferroptosis is recently discovered iron-dependent cell death fueled by lipid peroxidation, which differs from necrosis and apoptosis [322-324]. Mitochondrial metabolism involved series of substrates consumption, is primary source of ROS via Fenton reaction that ferrous iron mixed with hydrogen peroxide $\left(\mathrm{H}_{2} \mathrm{O}_{2}\right)$ is equipped with strong oxidizability to oxidize many known intracellular compounds such as carboxylic acids, alcohols and esters into inorganic states with significant oxidation effect [325]. Emerging studies has revealed ROS accumulation in a variety of cells including those within malignancies. Interestingly, it's reported that hypoxic tumors with HIF-1 over-expression inhibits acyl-CoA dehydrogenases leads to tumor progression via ROS alteration [209]. Over the past 20 years, small-molecule inhibitors, including system $\mathrm{x}_{\mathrm{c}}$-Inhibitors, GPX4 inhibitors, RTAs, CoQ10 pathway inhibitors, endoperoxides, and iron chelators and sources inhibitors etc., have been applied in ferroptosis-associated diseases [322], and mechanisms behind these inhibition effects may reappear in HIF signaling, which remains under-reported.

Anti-tumor therapy, in addition to established antiangiogenic therapy, targeting VHL loss and BET inhibition, also has the sustainable treatment based on the potential crosstalk between HIFs and ferroptosis, and targeting CAFs. Epigenetic intervention mediated by 
small molecule inhibitors are on the way, and higher efficacy may derived from combined joint therapy.

\section{Conclusion and perspectives}

Hypoxia affects tumor progression via various epigenetic modifications, including acetylation, methylation and demethylation and so on, which leads to tumor genomic instability due to tumor and tissue speficity or altered microenvironment. HIF- $\alpha$ activity plays a pivotal role in metabolic reprogramming, for example, special enzymes are activated by HIF- $\alpha$ family to adapt to the obligate metabolic demands, in turn, produced metabolites, including succinate, fumarate, pyruvate, lactate and oxaloacetate etc., affect the HIF proteins stability due to lossof-function of PHD. Despite of crosstalk between intracellular metabolites production and subsequent metabolic genes activation, EMT is also affected by HIF- $\alpha$ via epigenetic remodelers, notably, HIF- $1 \alpha$ promotes P4HA1 and P4HA2 transcriptional activities to further contributes to the formation of collagen, and $\alpha-$ ketoglutarate modulation of P4HA1 boosts the stability of HIF- $1 \alpha$, and further enhance the tumor progression. HIF signaling influences the EMT to promote metastasis, and primary tumors secrete factors which interacted with HIF- $\alpha$ to modify the niche into a survivable system so as to secondary tumor development and progression under hypoxia.

Anti-angiogenetic therapy may be exploited as recognized therapeutic stragedy through epigenetic intervention on VEGF family. Some small molecule tyrosine kinase inhibitors combines with VEGF blockade may improve therapeutic efficacy. However, VEGF signaling interacts with many other genes, it's critical to fully understand the complex crosstalk and exploit more therapies in face of low curative effects. Besides targeting VHL loss and BET inhibition therapy, given interaction between ferroptosis and HIFs on ROS affects, small-molecule inhibitors of ferroptosis is considered to use in hypoxic tumors treatments. HIF- $1 \alpha$ and HIF- $2 \alpha$ has been studied a lot, and mounting evidences indicated their important role in the regulation of hypoxic tumor progression, however the pathological role of HIF- $3 \alpha$ remains elusive and more efforts should be placed in understanding its pathological function. In fact, Ras/raf/MAPK, NF-kB, SREBP, Jak/Stat and Notch pathways are also play important roles in tumorigenesis, the interactions between them and HIF signaling may be more complex and need to be further studied.

Up to now, given the role of HIF signaling in hypoxic tumor progression, it's of great potential importance that targeting HIF- $\alpha$ directly or inhibiting the downstream genes in the crosstalk instead.

\section{Abbreviations}

HIFs: Hypoxia-inducible factors; PHD2: Prolyl hydroxylase domain protein 2; VHL: Hippel-Lindau tumor suppressor; ARNT: Aryl hydrocarbon receptor nuclear translocator; IncRNAs: long non-coding RNAs; TIMP2: Tissue inhibitor of metalloproteinases 2; HCC: Hepatocellular carcinoma; ODD: Oxygendependent degradation; OXPHOS: Oxidative phosphorylation; AMPK: AMPactivated protein kinase; ROS: Reactive oxygen species; NF-KB: Nuclear factor kappa-B; TNF-a: Tumor necrosis factor alpha; TAK: Tat-associated kinase complex catalytic subunit; IKK: I-kappaB kinase; CDK6: Cyclin-dependent kinase 6; PI3K: Phosphoinositide 3-kinase; PDK: Pyruvate dehydrogenase kinase; PKB: Protein kinase B; mTOR: Rapamycin; FoxO1: Forkhead box protein O1; DLL4: Delta like canonical Notch ligand 4; Notch: Neurogenic locus notch homolog; SAM: S-adenosine methionine; $5 \mathrm{mC}$ : 5-methylcytosine; CA9: Carbonic anhydrase 9; TET: Ten-eleven-translocation 5-methylcytosine dioxygenases; 2-OGDDs: 2-oxoglutarate-dependent dioxygenases;

CRS: Chronic restraint stress; SI-DhMLs: Hydroxymethylated loci; ChIPseq: Chromatin immunoprecipitation sequencing; HRE: Hypoxic response element; $\mathrm{m}^{6} \mathrm{~A}$ : N6-methyladenosine; GLP: G9a-like protein;

Ehmt2: Euchromatic histone lysine methyltransferase 2; VEGF: Vascular endothelial growth factor; JMJD: Jumonji domain; JmjC: Jumonji C; 2OG: 2oxoglutarate; FAD: Flavin adenine dinucleotide; PTC: Papillary thyroid carcinoma; TIP60: TAT-interactive protein 60; CBP: Cyclic AMP response element-binding protein; PCAF: CBP-associated factor; DANCR: Differentiation antagonizing non-protein coding RNA; MIIP: Migration and invasion inhibitory protein; a-KG: a-ketoglutarate; FBP1: Fructose-1,6-bisphosphatase; GLUT: Glucose transporter; HK: Hexokinase; PYG: Phosphorylase; PFKFB: 6phosphofructo-2-kinase/fructose-2,6-bisphosphatase; PDH: Pyruvate dehydrogenase; FA: Fatty acid; FASN: Fatty acid synthase; ACC: Acetyl-CoA carboxylase; FAO: Fatty acid oxidation; PTEN: Phosphatase and tensin homolog; HMGCS2: 3-hydroxy-3-methylglutaryl CoA synthase 2; IDH2: Isocitrate dehydrogenase 2; GDH: Glutamate dehydrogenase; HOXA9: Homeobox A9; CML: Chronic myelogenous leukemia; IPO7: Importin 7; ECM: Extracellular matrix; 5meC: 5-methylcytosine; MDSCs: Myeloid-derived suppressor cells; regDCs: regulatory dendritic cells; TAMs: Tumor-associated macrophages; NMT3A: DNA methyltransferase 3A; EZH2: Enhancer of zeste homolog 2; Mcrc: Metastatic colorectal cancer; HA: Hyaluronic acid; LOXL2: Lysyl oxidase-like protein 2; L1CAM: L1 cell adhesion molecule; CYTIP: Cytohesin 1 interacting protein; PRC2: Polycomb repressive complex 2; WDR5: WD repeat containing protein 5; HMT: Histone methyltransferase; TUG1: Taurine upregulated gene 1; CAFs: Cancer-associated fibroblasts; UBE2CP3: Ubiquitin conjugated enzyme E2C pseudogene 3; HUVEC: Human umbilical vein endothelial cell; BET: Bromodomain extralterminal proteins; PIGF: Placenta growth factor; NRPs: Neuropilin family; Sema3A: Semaphorin 3A; STS: Soft tissue sarcomas; TSC1/2: Tuberous Sclerosis Complex 1/2; INSI G2: Insulin induced gene 2; PLIN2: Lipogenic protein perilipin 2; CPT1A: Carnitine palmitoyltransferase 1A; OTUD6B: OTU deubiquitinase 6B; WSB1: Trp-Asp repeat and suppressors of cytokine signaling box-containing protein 1; UCP: E2-EPF ubiquitin carrier protein; CSF1: Colony stimulating factor $1 ; \mathrm{H}_{2} \mathrm{O}_{2}$ : Hydrogen peroxide

\section{Acknowledgements}

Not applicable.

\section{Authors' contributions}

Tiansheng Li contributed to drafting and editing of the manuscript, deserving the first authorship. Ying Shi and Yongguang Tao designed, revised and finalized the manuscript. Chao Mao participated in revision and coordination, and contributed to literature search. Xiang Wang participated in revision and coordination. All authors contributed to data analysis, drafting and revising the paper and agreed to be accountable for all aspects of the work. All authors read and approve the final manuscript.

\section{Funding}

This work was supported by grants from the National Natural Science Foundation of China [81672787(YT); 81872285(YS)], China Postdoctoral Science Foundation [2019 M652804 (CM)], Hunan Provincial Key Area R\&D Programs [2019SK2253 (XW)].

Availability of data and materials Not applicable. 


\section{Ethics approval and consent to participate}

Not applicable.

\section{Consent for publication}

Not applicable.

\section{Competing interests}

The authors declare that they have no competing interests.

\section{Author details}

${ }^{1} \mathrm{NHC}$ Key Laboratory of Carcinogenesis and Hunan Key Laboratory of Translational Radiation Oncology, Hunan Cancer Hospital and The Affiliated Cancer Hospital of Xiangya School of Medicine, Central South University, Changsha, Hunan, China. ${ }^{2}$ Key Laboratory of Carcinogenesis and Cancer Invasion of the Chinese Ministry of Education, Cancer Research Institute, Central South University, Changsha, Hunan, China. ${ }^{3}$ Department of Thoracic Surgery, Second Xiangya Hospital, Central South University, Changsha 410011, China.

\section{Received: 27 May 2020 Accepted: 13 October 2020}

\section{Published online: 27 October 2020}

\section{References}

1. Lee P, Chandel NS, Simon MC. Cellular adaptation to hypoxia through hypoxia inducible factors and beyond. Nat Rev Mol Cell Biol. 2020;21(5): 268-83

2. Choudhry H, Harris AL. Advances in Hypoxia-Inducible Factor Biology. Cell Metab. 2018;27(2):281-98.

3. Nagy JA, Chang SH, Dvorak AM, Dvorak HF. Why are tumour blood vessels abnormal and why is it important to know? Br J Cancer. 2009;100(6):865-9.

4. Wang GL, Jiang BH, Rue EA, Semenza GL. Hypoxia-inducible factor 1 is a basic-helix-loop-helix-PAS heterodimer regulated by cellular $\mathrm{O} 2$ tension. Proc Natl Acad Sci U S A. 1995;92(12):5510-4.

5. Gilkes DM, Semenza GL, Wirtz D. Hypoxia and the extracellular matrix: drivers of tumour metastasis. Nat Rev Cancer. 2014;14(6):430-9.

6. Yang L, Shi P, Zhao G, Xu J, Peng W, Zhang J, et al. Targeting cancer stem cell pathways for cancer therapy. Signal Transduct Target Ther. 2020;5(1):8.

7. Keith B, Simon MC. Hypoxia-inducible factors, stem cells, and cancer. Cell. 2007;129(3):465-72.

8. Ye Y, Hu Q, Chen H, Liang K, Yuan Y, Xiang Y, et al. Characterization of Hypoxia-associated Molecular Features to Aid Hypoxia-Targeted Therapy. Nat Metab. 2019;1(4):431-44.

9. Wallace EM, Rizzi JP, Han G, Wehn PM, Cao Z, Du X, et al. A Small-Molecule Antagonist of HIF2a Is Efficacious in Preclinical Models of Renal Cell Carcinoma. Cancer Res. 2016;76(18):5491-500.

10. Arcasoy MO, Amin K, Chou SC, Haroon ZA, Varia M, Raleigh JA. Erythropoietin and erythropoietin receptor expression in head and neck cancer: relationship to tumor hypoxia. Clin Cancer Res. 2005;11(1):20-7.

11. LaGory EL, Giaccia AJ. The ever-expanding role of HIF in tumour and stromal biology. Nat Cell Biol. 2016;18(4):356-65.

12. Vaupel $P$, Mayer A. Hypoxia in cancer: significance and impact on clinical outcome. Cancer Metastasis Rev. 2007;26(2):225-39.

13. Gentric G, Mieulet V, Mechta-Grigoriou F. Heterogeneity in Cancer Metabolism: New Concepts in an Old Field. Antioxid Redox Signal. 2017 26(9):462-85.

14. Pavlova NN, Thompson CB. The Emerging Hallmarks of Cancer Metabolism. Cell Metab. 2016;23(1):27-47.

15. DeBerardinis RJ, Chandel NS. Fundamentals of cancer metabolism. Sci Adv. 2016;2(5):e1600200.

16. Ning XH, Li T, Gong YQ, He Q, Shen QI, Peng SH, et al. Association between FBP1 and hypoxia-related gene expression in clear cell renal cell carcinoma. Oncol Lett. 2016;11(6):4095-8

17. Arjumand $\mathrm{W}$, Sultana S. Role of VHL gene mutation in human renal cell carcinoma. Tumour Biol. 2012;33(1):9-16.

18. Semenza GL. Hypoxia-inducible factors: mediators of cancer progression and targets for cancer therapy. Trends Pharmacol Sci. 2012;33(4):207-14.

19. Semenza GL. HIF-1 mediates metabolic responses to intratumoral hypoxia and oncogenic mutations. J Clin Invest. 2013;123(9):3664-71.

20. Qi B, Chen HL, Shang D, Dong Y, Zhang GX, Yu L. Effects of hypoxiainducible factor-1alpha and matrix metalloproteinase-9 on alveolar-capillary barrier disruption and lung edema in rat models of severe acute pancreatitis-associated lung injury. Exp Ther Med. 2014;8(3):899-906.

21. Fujita N, Chiba K, Shapiro IM, Risbud MV. HIF-1alpha and HIF-2alpha degradation is differentially regulated in nucleus pulposus cells of the intervertebral disc. J Bone Miner Res. 2012;27(2):401-12.

22. Liu N, Luo J, Kuang D, Xu S, Duan Y, Xia Y, et al. Lactate inhibits ATP6V0d2 expression in tumor-associated macrophages to promote HIF-2alpha-mediated tumor progression. J Clin Invest. 2019;129(2): 631-46.

23. Zhang P, Yao Q, Lu L, Li Y, Chen PJ, Duan C. Hypoxia-inducible factor 3 is an oxygen-dependent transcription activator and regulates a distinct transcriptional response to hypoxia. Cell Rep. 2014;6(6):1110-21.

24. Heikkila M, Pasanen A, Kivirikko Kl, Myllyharju J. Roles of the human hypoxiainducible factor (HIF)-3alpha variants in the hypoxia response. Cell Mol Life Sci. 2011;68(23):3885-901.

25. Folkman J. Tumor angiogenesis: therapeutic implications. N Engl J Med. 1971;285(21):1182-6.

26. Kai AK, Chan LK, Lo RC, Lee JM, Wong CC, Wong JC, et al. Down-regulation of TIMP2 by HIF-1alpha/miR-210/HIF-3alpha regulatory feedback circuit enhances cancer metastasis in hepatocellular carcinoma. Hepatology. 2016; 64(2):473-87.

27. McGuirk S, Audet-Delage Y, St-Pierre J. Metabolic Fitness and Plasticity in Cancer Progression. Trends Cancer. 2020;6(1):49-61.

28. Mclntyre A, Harris AL. Metabolic and hypoxic adaptation to anti-angiogenic therapy: a target for induced essentiality. EMBO Mol Med. 2015;7(4):368-79.

29. Semenza GL. Defining the role of hypoxia-inducible factor 1 in cancer biology and therapeutics. Oncogene. 2010;29(5):625-34.

30. Tarade D, Robinson CM, Lee JE, Ohh M. HIF-2alpha-pVHL complex reveals broad genotype-phenotype correlations in HIF-2alpha-driven disease. Nat Commun. 2018;9(1):3359.

31. Qin Y, Liu HJ, Li M, Zhai DH, Tang YH, Yang L, et al. Salidroside improves the hypoxic tumor microenvironment and reverses the drug resistance of platinum drugs via HIF-1alpha signaling pathway. EBioMedicine. 2018;38:2536.

32. Valsecchi $R$, Coltella N, Belloni D, Ponente M, Ten Hacken E, Scielzo C, et al. HIF-1alpha regulates the interaction of chronic lymphocytic leukemia cells with the tumor microenvironment. Blood. 2016;127(16):1987-97.

33. Zhang J, Zhang Q, Lou Y, Fu Q, Chen Q, Wei T, et al. Hypoxia-inducible factor-1alpha/interleukin-1 beta signaling enhances hepatoma epithelialmesenchymal transition through macrophages in a hypoxic-inflammatory microenvironment. Hepatology. 2018;67(5):1872-89.

34. Zhang L, Huang ST, Feng YL, Wan T, Gu HF, Xu J, et al. The Bidirectional Regulation between MYL5 and HIF-1alpha Promotes Cervical Carcinoma Metastasis. Theranostics. 2017:7(15):3768-80.

35. Zheng $Y$, Ni Y, Huang X, Wang Z, Han W. Overexpression of HIF-1alpha indicates a poor prognosis in tongue carcinoma and may be associated with tumour metastasis. Oncol Lett. 2013;5(4):1285-9.

36. Lai HH, Li JN, Wang MY, Huang HY, Croce CM, Sun HL, et al. HIF-1alpha promotes autophagic proteolysis of Dicer and enhances tumor metastasis. J Clin Invest. 2018;128(2):625-43.

37. Azoitei N, Becher A, Steinestel K, Rouhi A, Diepold K, Genze F, et al. PKM2 promotes tumor angiogenesis by regulating HIF-1alpha through NF-kappaB activation. Mol Cancer. 2016;15:3.

38. Baker LC, Boult JK, Walker-Samuel S, Chung YL, Jamin Y, Ashcroft M, et al. The HIF-pathway inhibitor NSC-134754 induces metabolic changes and anti-tumour activity while maintaining vascular function. Br J Cancer. 2012 106(10):1638-47.

39. Yamakuchi M, Lotterman CD, Bao C, Hruban RH, Karim B, Mendell JT, et al P53-induced microRNA-107 inhibits HIF-1 and tumor angiogenesis. Proc Natl Acad Sci U S A. 2010;107(14):6334-9.

40. Skuli N, Liu L, Runge A, Wang T, Yuan L, Patel S, et al. Endothelial deletion of hypoxia-inducible factor-2alpha (HIF-2alpha) alters vascular function and tumor angiogenesis. Blood. 2009;114(2):469-77.

41. Lall R, Ganapathy S, Yang M, Xiao S, Xu T, Su H, et al. Low-dose radiation exposure induces a HIF-1-mediated adaptive and protective metabolic response. Cell Death Differ. 2014;21(5):836-44.

42. Rey S, Luo W, Shimoda LA, Semenza GL. Metabolic reprogramming by HIF-1 promotes the survival of bone marrow-derived angiogenic cells in ischemic tissue. Blood. 2011;117(18):4988-98.

43. Hulea L, Gravel SP, Morita M, Cargnello M, Uchenunu O, Im YK, et al. Translational and HIF-1alpha-Dependent Metabolic Reprogramming 
Underpin Metabolic Plasticity and Responses to Kinase Inhibitors and Biquanides. Cell Metab. 2018;28(6):817-832.e818.

44. Harvey ZH, Chen Y, Jarosz DF. Protein-Based Inheritance: Epigenetics beyond the Chromosome. Mol Cell. 2018;69(2):195-202.

45. Dawson MA. The cancer epigenome: Concepts, challenges, and therapeutic opportunities. Science. 2017;355(6330):1147-52.

46. Zhang L, Liang Y, Li S, Zeng F, Meng Y, Chen Z, et al. The interplay of circulating tumor DNA and chromatin modification, therapeutic resistance, and metastasis. Mol Cancer. 2019;18(1):36.

47. Yan B, Liu S, Shi Y, Liu N, Chen L, Wang X, et al. Activation of AhR with nuclear IKKalpha regulates cancer stem-like properties in the occurrence of radioresistance. Cell Death Dis. 2018;9(5):490.

48. Semenza GL. Oxygen sensing, hypoxia-inducible factors, and disease pathophysiology. Annu Rev Pathol. 2014:9:47-71.

49. Wiesener MS, Jurgensen JS, Rosenberger C, Scholze CK, Horstrup JH,

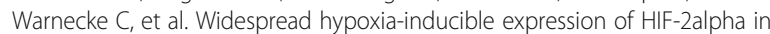
distinct cell populations of different organs. Faseb j. 2003;17(2):271-3.

50. Huang LE, Gu J, Schau M, Bunn HF. Regulation of hypoxia-inducible factor 1alpha is mediated by an O2-dependent degradation domain via the ubiquitin-proteasome pathway. Proc Natl Acad Sci U S A. 1998;95(14):798792.

51. Robinson CM, Ohh M. The multifaceted von Hippel-Lindau tumour suppressor protein. FEBS Lett. 2014;588(16):2704-11.

52. Perrotta S, Roberti D, Bencivenga D, Corsetto P, O'Brien KA, Caiazza M, et al. Effects of Germline VHL Deficiency on Growth, Metabolism, and Mitochondria. N Engl J Med. 2020;382(9):835-44.

53. Choueiri TK, Fay AP, Gagnon R, Lin Y, Bahamon B, Brown V, et al. The role of aberrant VHL/HIF pathway elements in predicting clinical outcome to pazopanib therapy in patients with metastatic clear-cell renal cell carcinoma. Clin Cancer Res. 2013;19(18):5218-26

54. Chesnel F, Hascoet P, Gagne JP, Couturier A, Jouan F, Poirier GG, et al. The von Hippel-Lindau tumour suppressor gene: uncovering the expression of the PVHL172 isoform. Br J Cancer. 2015;113(2):336-44.

55. Tirosh A, Sadowski SM, Linehan WM, Libutti SK, Patel D, Nilubol N, et al. Association of VHL Genotype With Pancreatic Neuroendocrine Tumor Phenotype in Patients With von Hippel-Lindau Disease. JAMA Oncol. 2018; 4(1):124-6.

56. Sim J, Cowburn AS, Palazon A, Madhu B, Tyrakis PA, Macias D, et al. The Factor Inhibiting HIF Asparaginyl Hydroxylase Regulates Oxidative Metabolism and Accelerates Metabolic Adaptation to Hypoxia. Cell Metab. 2018;27(4):898-913.e897.

57. Jia D, Lu M, Jung KH, Park JH, Yu L, Onuchic JN, et al. Elucidating cancer metabolic plasticity by coupling gene regulation with metabolic pathways. Proc Natl Acad Sci U S A. 2019;116(9):3909-18.

58. Zhou X, Chen J, Yi G, Deng M, Liu H, Liang M, et al. Metformin suppresses hypoxia-induced stabilization of HIF-1alpha through reprogramming of oxygen metabolism in hepatocellular carcinoma. Oncotarget. 2016;7(1):87384.

59. Iommarini L, Kurelac I, Capristo M, Calvaruso MA, Giorgio V, Bergamini C, et al. Different mtDNA mutations modify tumor progression in dependence of the degree of respiratory complex I impairment. Hum Mol Genet. 2014; 23(6):1453-66.

60. Ellinghaus P, Heisler I, Unterschemmann K, Haerter M, Beck H, Greschat S, et al. BAY 87-2243, a highly potent and selective inhibitor of hypoxiainduced gene activation has antitumor activities by inhibition of mitochondrial complex I. Cancer Med. 2013;2(5):611-24.

61. Yu L, Lu M, Jia D, Ma J, Ben-Jacob E, Levine H, et al. Modeling the Genetic Regulation of Cancer Metabolism: Interplay between Glycolysis and Oxidative Phosphorylation. Cancer Res. 2017;77(7):1564-74.

62. Hascoet $P$, Chesnel F, Jouan F, Le Goff C, Couturier A, Darrigrand E, et al. The PVHL172 isoform is not a tumor suppressor and up-regulates a subset of pro-tumorigenic genes including TGFB1 and MMP13. Oncotarget. 2017; 8(44):75989-6002.

63. Jin $\mathrm{P}$, Shin SH, Chun YS, Shin HW, Shin YJ, Lee Y, et al. Astrocyte-derived CCL2O reinforces HIF-1-mediated hypoxic responses in glioblastoma by stimulating the CCR6-NF-KB signaling pathway. Oncogene. 2018;37(23): 3070-87.

64. Azoitei N, Becher A, Steinestel K, Rouhi A, Diepold K, Genze F, et al. PKM2 promotes tumor angiogenesis by regulating HIF-1a through NF-KB activation. Mol Cancer. 2016:15:3.
65. Rius J, Guma M, Schachtrup C, Akassoglou K, Zinkernagel AS, Nizet V, et al. $\mathrm{NF}$-kappaB links innate immunity to the hypoxic response through transcriptional regulation of HIF-1alpha. Nature. 2008;453(7196):807-11.

66. Bandarra D, Biddlestone J, Mudie S, Muller HA, Rocha S. HIF-1alpha restricts NF-kappaB-dependent gene expression to control innate immunity signals. Dis Model Mech. 2015;8(2):169-81.

67. van Uden P, Kenneth NS, Webster R, Muller HA, Mudie S, Rocha S. Evolutionary conserved regulation of HIF-1 beta by NF-kappaB. PLoS Genet. 2011;7(1):e1001285.

68. D'Ignazio L, Batie M, Rocha S. TNFSF14/LIGHT, a Non-Canonical NF-kappaB Stimulus, Induces the HIF Pathway. Cells. 2018;7(8):102.

69. Xiang $T$, Lin $Y X, M a W$, Zhang $H J$, Chen KM, He GP, et al. Vasculogenic mimicry formation in EBV-associated epithelial malignancies. Nat Commun. 2018;9(1):5009.

70. Li S, Huang C, Hu G, Ma J, Chen Y, Zhang J, et al. Tumor-educated B cells promote renal cancer metastasis via inducing the IL-1 beta/HIF-2alpha/ Notch1 signals. Cell Death Dis. 2020;11(3):163.

71. Wu D, Su X, Lu J, Li S, Hood BL, Vasile S, et al. Bidirectional modulation of HIF-2 activity through chemical ligands. Nat Chem Biol. 2019;15(4):367-76.

72. Bao L, Chen Y, Lai HT, Wu SY, Wang JE, Hatanpaa K, et al. Methylation of hypoxia-inducible factor (HIF)-1a by G9a/GLP inhibits HIF-1 transcriptional activity and cell migration. Nucleic Acids Res. 2018;46(13):6576-91.

73. Rohwer $\mathrm{N}$, Jumpertz $\mathrm{S}$, Erdem $\mathrm{M}$, Egners $\mathrm{A}$, Warzecha $\mathrm{KT}$, Fragoulis $\mathrm{A}$, et al. Non-canonical HIF-1 stabilization contributes to intestinal tumorigenesis. Oncogene. 2019:38(28):5670-85.

74. Luo W, Wang Y. Epigenetic regulators: multifunctional proteins modulating hypoxia-inducible factor-alpha protein stability and activity. Cell Mol Life Sci. 2018;75(6):1043-56.

75. Thienpont B, Steinbacher J, Zhao H, D'Anna F, Kuchnio A, Ploumakis A, et al. Tumour hypoxia causes DNA hypermethylation by reducing TET activity. Nature. 2016;537(7618):63-8.

76. Esteller M. Epigenetics in cancer. N Engl J Med. 2008;358(11):1148-59.

77. Wang Q, Yu G, Ming X, Xia W, Xu X, Zhang Y, et al. Imprecise DNMT1 activity coupled with neighbor-guided correction enables robust yet flexible epigenetic inheritance. Nat Genet. 2020;52(8):828-39.

78. Herman JG, Graff JR, Myöhänen S, Nelkin BD, Baylin SB. Methylation-specific PCR: a novel PCR assay for methylation status of $\mathrm{CpG}$ islands. Proc Natl Acad Sci U S A. 1996;93(18):9821-6.

79. Kuroki T, Trapasso F, Yendamuri S, Matsuyama A, Alder H, Mori M, et al. Allele loss and promoter hypermethylation of VHL, RAR-beta, RASSF1A, and FHIT tumor suppressor genes on chromosome $3 p$ in esophageal squamous cell carcinoma. Cancer Res. 2003;63(13):3724-8.

80. Schmitt AM, Schmid S, Rudolph T, Anlauf M, Prinz C, Klöppel G, et al. VHL inactivation is an important pathway for the development of malignant sporadic pancreatic endocrine tumors. Endocr Relat Cancer. 2009;16(4): 1219-27.

81. Koslowski M, Luxemburger U, Türeci O, Sahin U. Tumor-associated CpG demethylation augments hypoxia-induced effects by positive autoregulation of HIF-1a. Oncogene. 2011;30(7):876-82.

82. Laukka T, Mariani CJ, Ihantola T, Cao JZ, Hokkanen J, Kaelin WG Jr, et al. Fumarate and Succinate Regulate Expression of Hypoxia-inducible Genes via TET Enzymes. J Biol Chem. 2016;291(8):4256-65.

83. Wang J, Zhang D, Du J, Zhou C, Li Z, Liu X, et al. Tet1 facilitates hypoxia tolerance by stabilizing the HIF-a proteins independent of its methylcytosine dioxygenase activity. Nucleic Acids Res. 2017;45(22):1270014.

84. Lio CJ, Yuita H, Rao A. Dysregulation of the TET family of epigenetic regulators in lymphoid and myeloid malignancies. Blood. 2019;134(18): 1487-97.

85. Ghanty U, Wang T, Kohli RM. Nucleobase Modifiers Identify TET Enzymes as Bifunctional DNA Dioxygenases Capable of Direct N-Demethylation. Angew Chem Int Ed Engl. 2020;59(28):11312-5.

86. Cheng $Y$, Sun $M$, Chen L, Li Y, Lin L, Yao B, et al. Ten-Eleven Translocation Proteins Modulate the Response to Environmental Stress in Mice. Cell Rep. 2018;25(11):3194-3203.e3194.

87. Antunes C, Sousa N, Pinto L, Marques CJ. TET enzymes in neurophysiology and brain function. Neurosci Biobehav Rev. 2019;102:337-44.

88. Mariani CJ, Vasanthakumar A, Madzo J, Yesilkanal A, Bhagat T, Yu Y, et al. TET1-mediated hydroxymethylation facilitates hypoxic gene induction in neuroblastoma. Cell Rep. 2014;7(5):1343-52. 
89. Chen XY, Zhang J, Zhu JS. The role of $m$ (6) A RNA methylation in human cancer. Mol Cancer. 2019;18(1):103.

90. Zhao BS, Roundtree IA, He C. Post-transcriptional gene regulation by mRNA modifications. Nat Rev Mol Cell Biol. 2017;18(1):31-42.

91. Lan Q, Liu PY, Haase J, Bell JL, Hüttelmaier S, Liu T. The Critical Role of RNA m(6) A Methylation in Cancer. Cancer Res. 2019;79(7):1285-92.

92. Green NH, Galvan DL, Badal SS, Chang BH, LeBleu VS, Long J, et al. MTHFD2 links RNA methylation to metabolic reprogramming in renal cell carcinoma. Oncogene. 2019;38(34):6211-25.

93. Pikman Y, Puissant A, Alexe G, Furman A, Chen LM, Frumm SM, et al. Targeting MTHFD2 in acute myeloid leukemia. J Exp Med. 2016;213(7):1285306.

94. Kim I, Park JW. Hypoxia-driven epigenetic regulation in cancer progression: A focus on histone methylation and its modifying enzymes. Cancer Lett. 2020:489:41-9

95. Casciello F, Al-Ejeh F, Kelly G, Brennan DJ, Ngiow SF, Young A, et al. G9a drives hypoxia-mediated gene repression for breast cancer cell survival and tumorigenesis. Proc Natl Acad Sci U S A. 2017;114(27): 7077-82.

96. Li Y, Guo X, Sun L, Xiao J, Su S, Du S, et al. N(6)-Methyladenosine Demethylase FTO Contributes to Neuropathic Pain by Stabilizing G9a Expression in Primary Sensory Neurons. Adv Sci (Weinh). 2020;7(13): 1902402.

97. Oh SY, Seok JY, Choi YS, Lee SH, Bae JS, Lee YM. The Histone Methyltransferase Inhibitor BIX01294 Inhibits HIF-1a Stability and Angiogenesis. Mol Cells. 2015;38(6):528-34.

98. Lee JS, Kim Y, Bhin J, Shin HJ, Nam HJ, Lee SH, et al. Hypoxia-induced methylation of a pontin chromatin remodeling factor. Proc Natl Acad Sci U S A. 2011;108(33):13510-5.

99. Kang J, Shin $\mathrm{SH}$, Yoon H, Huh J, Shin HW, Chun YS, et al. FlH Is an Oxygen Sensor in Ovarian Cancer for G9a/GLP-Driven Epigenetic Regulation of Metastasis-Related Genes. Cancer Res. 2018;78(5):1184-99.

100. Yang SJ, Park YS, Cho JH, Moon B, An HJ, Lee JY, et al. Regulation of hypoxia responses by flavin adenine dinucleotide-dependent modulation of HIF-1a protein stability. Embo J. 2017;36(8):1011-28.

101. Yang J, Chen S, Yang Y, Ma X, Shao B, Yang S, et al. Jumonji domaincontaining protein 6 protein and its role in cancer. Cell Prolif. 2020;53(2): e12747.

102. Lee YF, Miller LD, Chan XB, Black MA, Pang B, Ong CW, et al. JMJD6 is a driver of cellular proliferation and motility and a marker of poor prognosis in breast cancer. Breast Cancer Res. 2012;14(3):R85.

103. Liu X, Si W, Liu X, He L, Ren J, Yang Z, et al. JMJD6 promotes melanoma carcinogenesis through regulation of the alternative splicing of PAK1, a key MAPK signaling component. Mol Cancer. 2017: 16(1):175

104. Lee CR, Lee SH, Rigas NK, Kim RH, Kang MK, Park NH, et al. Elevated expression of JMJD6 is associated with oral carcinogenesis and maintains cancer stemness properties. Carcinogenesis. 2016;37(2):119-28.

105. Wan J, Xu W, Zhan J, Ma J, Li X, Xie Y, et al. PCAF-mediated acetylation of transcriptional factor HOXB9 suppresses lung adenocarcinoma progression by targeting oncogenic protein JMJD6. Nucleic Acids Res. 2016;44(22): 10662-75.

106. Wan J, Liu H, Yang L, Ma L, Liu J, Ming L. JMJD6 promotes hepatocellular carcinoma carcinogenesis by targeting CDK4. Int J Cancer. 2019;144(10): 2489-500.

107. Wang F, He L, Huangyang P, Liang J, Si W, Yan R, et al. JMJD6 promotes colon carcinogenesis through negative regulation of $\mathrm{p} 53$ by hydroxylation. PLoS Biol. 2014;12(3):e1001819.

108. Zheng H, Tie Y, Fang Z, Wu X, Yi T, Huang S, et al. Jumonji domaincontaining 6 (JMJD6) identified as a potential therapeutic target in ovarian cancer. Signal Transduct Target Ther. 2019;4(1):24.

109. Zhou DX, Zhou D, Zhan SQ, Wang P, Qin K, Gan W, et al. Inhibition of JMJD6 expression reduces the proliferation, migration and invasion of neuroglioma stem cells. Neoplasma. 2017;64(5):700-8.

110. Lian Y, Yan C, Lian Y, Yang R, Chen Q, Ma D, et al. Long intergenic nonprotein-coding RNA 01446 facilitates the proliferation and metastasis of gastric cancer cells through interacting with the histone lysine-specific demethylase LSD1. Cell Death Dis. 2020;11(7):522.

111. Amente S, Lania L, Majello B. The histone LSD1 demethylase in stemness and cancer transcription programs. Biochim Biophys Acta. 2013;1829(10): 981-6.
112. Long M, Zhu Y, Chen Z, Lin S, Peng X, Luo D, et al. Lysine-Specific Demethylase 1 Affects the Progression of Papillary Thyroid Carcinoma via HIF1a and microRNA-146a. J Clin Endocrinol Metab. 2020;105(7):dgaa182.

113. Gu F, Lin Y, Wang Z, Wu X, Ye Z, Wang Y, et al. Biological roles of LSD1 beyond its demethylase activity. Cell Mol Life Sci. 2020;77(17):3341-50.

114. Braun TP, Coblentz C, Smith BM, Coleman DJ, Schonrock Z, Carratt SA, et al. Combined inhibition of JAKJSTAT pathway and lysine-specific demethylase 1 as a therapeutic strategy in CSF3R/CEBPA mutant acute myeloid leukemia. Proc Natl Acad Sci U S A. 2020;117(24):13670-9.

115. Wass M, Göllner S, Besenbeck B, Schlenk RF, Mundmann P, Göthert JR, et al. A proof of concept phase $1 / /$ pilot trial of LSD1 inhibition by tranylcypromine combined with ATRA in refractory/relapsed AML patients not eligible for intensive therapy. Leukemia. 2020;1-11. https://doi.org/10. 1038/s41375-020-0892-z.

116. Luo W, Wang Y. Epigenetic regulators: multifunctional proteins modulating hypoxia-inducible factor-a protein stability and activity. Cell Mol Life Sci. 2018;75(6):1043-56.

117. Arany Z, Huang LE, Eckner R, Bhattacharya S, Jiang C, Goldberg MA, et al. An essential role for p300/CBP in the cellular response to hypoxia. Proc Natl Acad Sci U S A. 1996;93(23):12969-73.

118. Anastasi $\mathrm{S}$, Alemà S, Segatto O. Making sense of $\mathrm{Cbp} / \mathrm{p} 300$ loss of function mutations in skin tumorigenesis. J Pathol. 2020;250(1):3-6.

119. Reece KM, Richardson ED, Cook KM, Campbell TJ, Pisle ST, Holly AJ, et al. Epidithiodiketopiperazines (ETPs) exhibit in vitro antiangiogenic and in vivo antitumor activity by disrupting the HIF-1 a/p300 complex in a preclinical model of prostate cancer. Mol Cancer. 2014;13:91.

120. Iyer NG, Ozdag H, Caldas C. p300/CBP and cancer. Oncogene. 2004;23(24): 4225-31.

121. Liu J, He D, Cheng L, Huang C, Zhang Y, Rao X, et al. p300/CBP inhibition enhances the efficacy of programmed death-ligand 1 blockade treatment in prostate cancer. Oncogene. 2020;39(19):3939-51.

122. Kasper LH, Boussouar F, Boyd K, Xu W, Biesen M, Rehg J, et al. Two transactivation mechanisms cooperate for the bulk of HIF-1-responsive gene expression. Embo J. 2005;24(22):3846-58.

123. Yin S, Kaluz S, Devi NS, Jabbar AA, de Noronha RG, Mun J, et al. Arylsulfonamide $\mathrm{KCN} 1$ inhibits in vivo glioma growth and interferes with HIF signaling by disrupting HIF-1a interaction with cofactors p300/CBP. Clin Cancer Res. 2012;18(24):6623-33.

124. Lim JH, Lee YM, Chun YS, Chen J, Kim JE, Park JW. Sirtuin 1 modulates cellular responses to hypoxia by deacetylating hypoxia-inducible factor 1alpha. Mol Cell. 2010;38(6):864-78.

125. Geng H, Liu Q, Xue C, David LL, Beer TM, Thomas GV, et al. HIF1a protein stability is increased by acetylation at lysine 709. J Biol Chem. 2012;287(42): 35496-505.

126. Li J, Xi W, Li X, Sun H, Li Y. Advances in inhibition of protein-protein interactions targeting hypoxia-inducible factor- 1 for cancer therapy. Bioorg Med Chem. 2019;27(7):1145-58.

127. Wang J, He H, Chen B, Jiang G, Cao L, Jiang $H$, et al. Acetylation of XPF by TIP60 facilitates XPF-ERCC1 complex assembly and activation. Nat Commun. 2020;11(1):786.

128. Perez-Perri Jl, Dengler VL, Audetat KA, Pandey A, Bonner EA, Urh M, et al. The TIP60 Complex Is a Conserved Coactivator of HIF1A. Cell Rep. 2016; 16(1):37-47.

129. Hobbs CA, Wei G, DeFeo K, Paul B, Hayes CS, Gilmour SK. Tip60 protein isoforms and altered function in skin and tumors that overexpress ornithine decarboxylase. Cancer Res. 2006;66(16):8116-22.

130. Numata A, Kwok HS, Zhou QL, Li J, Tirado-Magallanes R, Espinosa Angarcia $\mathrm{V}$, et al. Lysine acetyltransferase Tip60 is required for hematopoietic stem cell maintenance. Blood. 2020;136(15):1735-47.

131. Luo L, Martin SC, Parkington J, Cadena SM, Zhu J, Ibebunjo C, et al. HDAC4 Controls Muscle Homeostasis through Deacetylation of Myosin Heavy Chain, PGC-1a, and Hsc70. Cell Rep. 2019;29(3):749-763.e712.

132. Nguyen HCB, Adlanmerini M, Hauck AK, Lazar MA. Dichotomous engagement of $\mathrm{HDAC} 3$ activity governs inflammatory responses. Nature. 2020;584(7820):286-90.

133. Geng H, Harvey CT, Pittsenbarger J, Liu Q, Beer TM, Xue C, et al. HDAC4 protein regulates HIF1a protein lysine acetylation and cancer cell response to hypoxia. J Biol Chem. 2011;286(44):38095-102.

134. Zhang Y, Ren YJ, Guo LC, Ji C, Hu J, Zhang HH, et al. Nucleus accumbensassociated protein-1 promotes glycolysis and survival of hypoxic tumor cells via the HDAC4-HIF-1a axis. Oncogene. 2017;36(29):4171-81. 
135. Chen S, Yin C, Lao T, Liang D, He D, Wang C, et al. AMPK-HDAC5 pathway facilitates nuclear accumulation of HIF-1a and functional activation of HIF-1 by deacetylating Hsp70 in the cytosol. Cell Cycle. 2015;14(15):2520-36.

136. Qian DZ, Kachhap SK, Collis SJ, Verheul HM, Carducci MA, Atadja P, et al. Class II histone deacetylases are associated with VHL-independent regulation of hypoxia-inducible factor 1 alpha. Cancer Res. 2006;66(17): 8814-21.

137. Kong X, Lin Z, Liang D, Fath D, Sang N, Caro J. Histone deacetylase inhibitors induce $\mathrm{VHL}$ and ubiquitin-independent proteasomal degradation of hypoxia-inducible factor 1alpha. Mol Cell Biol. 2006;26(6):2019-28.

138. Zhou W, Yang J, Saren G, Zhao H, Cao K, Fu S, et al. HDAC6-specific inhibitor suppresses Th17 cell function via the HIF-1a pathway in acute lung allograft rejection in mice. Theranostics. 2020;10(15):6790-805.

139. Bae J, Hideshima T, Tai YT, Song Y, Richardson P, Raje N, et al. Histone deacetylase (HDAC) inhibitor ACY241 enhances anti-tumor activities of antigen-specific central memory cytotoxic T lymphocytes against multiple myeloma and solid tumors. Leukemia. 2018;32(9):1932-47.

140. Guerriero JL, Sotayo A, Ponichtera HE, Castrillon JA, Pourzia AL, Schad S, et al. Class Ila HDAC inhibition reduces breast tumours and metastases through anti-tumour macrophages. Nature. 2017;543(7645):428-32.

141. Yin L, Liu Y, Peng Y, Peng Y, Yu X, Gao Y, et al. PARP inhibitor veliparib and HDAC inhibitor SAHA synergistically co-target the UHRF1/BRCA1 DNA damage repair complex in prostate cancer cells. J Exp Clin Cancer Res. 2018; 37(1):153.

142. Jeong JW, Bae MK, Ahn MY, Kim SH, Sohn TK, Bae MH, et al. Regulation and destabilization of HIF-1alpha by ARD1-mediated acetylation. Cell. 2002; 111(5):709-20.

143. Zhang Y, Zhou H, Tao Y, Liu X, Yuan Z, Nie C. ARD1 contributes to IKK $\beta$ mediated breast cancer tumorigenesis. Cell Death Dis. 2018;9(9):860

144. Seo JH, Park JH, Lee EJ, Vo TT, Choi H, Kim JY, et al. ARD1-mediated Hsp70 acetylation balances stress-induced protein refolding and degradation. Nat Commun. 2016;7:12882.

145. Yoon H, Kim HL, Chun YS, Shin DH, Lee KH, Shin CS, et al. NAA10 controls osteoblast differentiation and bone formation as a feedback regulator of Runx2. Nat Commun. 2014;5:5176.

146. Kang J, Chun YS, Huh J, Park JW. FIH permits NAA10 to catalyze the oxygendependent lysyl-acetylation of HIF-1alpha. Redox Biol. 2018;19:364-74.

147. Cho SW, Xu J, Sun R, Mumbach MR, Carter AC, Chen YG, et al. Promoter of IncRNA Gene PVT1 Is a Tumor-Suppressor DNA Boundary Element. Cell. 2018;173(6):1398-1412.e1322.

148. Wang Y, Chen W, Lian J, Zhang H, Yu B, Zhang M, et al. The IncRNA PVT1 regulates nasopharyngeal carcinoma cell proliferation via activating the KAT2A acetyltransferase and stabilizing HIF-1a. Cell Death Differ. 2020;27(2): 695-710.

149. Wen X, Liu X, Mao YP, Yang XJ, Wang YQ, Zhang PP, et al. Long non-coding RNA DANCR stabilizes HIF-1a and promotes metastasis by interacting with NF90/NF45 complex in nasopharyngeal carcinoma. Theranostics. 2018;8(20): 5676-89.

150. Lee S, Hallis SP, Jung KA, Ryu D, Kwak MK. Impairment of HIF-1a-mediated metabolic adaption by NRF2-silencing in breast cancer cells. Redox Biol. 2019;24:101210.

151. Kim TH, Hur EG, Kang SJ, Kim JA, Thapa D, Lee YM, et al. NRF2 blockade suppresses colon tumor angiogenesis by inhibiting hypoxia-induced activation of HIF-1a. Cancer Res. 2011;71(6):2260-75.

152. Niu Y, Jin Y, Deng SC, Deng SJ, Zhu S, Liu Y, et al. MiRNA-646-mediated reciprocal repression between $\mathrm{HIF-1a}$ and MIIP contributes to tumorigenesis of pancreatic cancer. Oncogene. 2018;37(13):1743-58.

153. Zeng $Z$, Xu FY, Zheng $H$, Cheng $P$, Chen QY, Ye Z, et al. LncRNAMTA2TR functions as a promoter in pancreatic cancer via driving deacetylation-dependent accumulation of HIF-1a. Theranostics. 2019; 9(18):5298-314

154. Chen T, Li J, Xu M, Zhao Q, Hou Y, Yao L, et al. PKCE phosphorylates MIIP and promotes colorectal cancer metastasis through inhibition of RelA deacetylation. Nat Commun. 2017:8(1):939.

155. Zhou C, Ji J, Cai Q, Shi M, Chen X, Yu Y, et al. MTA2 promotes gastric cancer cells invasion and is transcriptionally regulated by Sp1. Mol Cancer. 2013; 12(1):102.

156. Zhang $Y, \mathrm{Ng} \mathrm{HH}$, Erdjument-Bromage $\mathrm{H}$, Tempst $\mathrm{P}$, Bird A, Reinberg D. Analysis of the NuRD subunits reveals a histone deacetylase core complex and a connection with DNA methylation. Genes Dev. 1999;13(15):1924-35.
157. Denko NC. Hypoxia, HIF1 and glucose metabolism in the solid tumour. Nat Rev Cancer. 2008;8(9):705-13.

158. Dang CV. Cancer Metabolism: the Known, Unknowns. Biochim Biophys Acta Rev Cancer. 2018;1870(1):1.

159. Ozer A, Wu LC, Bruick RK. The candidate tumor suppressor ING4 represses activation of the hypoxia inducible factor (HIF). Proc Natl Acad Sci U S A. 2005;102(21):7481-6

160. Chen F, Chen J, Yang L, Liu J, Zhang X, Zhang Y, et al. Extracellular vesiclepackaged HIF-1alpha-stabilizing IncRNA from tumour-associated macrophages regulates aerobic glycolysis of breast cancer cells. Nat Cell Biol. 2019;21(4):498-510.

161. Tannahill GM, Curtis AM, Adamik J, Palsson-McDermott EM, McGettrick AF, Goel $\mathrm{G}$, et al. Succinate is an inflammatory signal that induces IL-1beta through HIF-1alpha. Nature. 2013;496(7444):238-42.

162. Kinnaird A, Dromparis P, Saleme B, Gurtu V, Watson K, Paulin R, et al. Metabolic Modulation of Clear-cell Renal Cell Carcinoma with Dichloroacetate, an Inhibitor of Pyruvate Dehydrogenase Kinase. Eur Urol. 2016;69(4):734-44.

163. Lampropoulou V, Sergushichev A, Bambouskova M, Nair S, Vincent EE, Loginicheva E, et al. Itaconate Links Inhibition of Succinate Dehydrogenase with Macrophage Metabolic Remodeling and Regulation of Inflammation. Cell Metab. 2016;24(1):158-66.

164. Gottlieb E, Tomlinson IP. Mitochondrial tumour suppressors: a genetic and biochemical update. Nat Rev Cancer. 2005;5(11):857-66.

165. Schulze A, Harris AL. How cancer metabolism is tuned for proliferation and vulnerable to disruption. Nature. 2012;491(7424):364-73.

166. Waitkus MS, Diplas BH, Yan H. Biological Role and Therapeutic Potential of IDH Mutations in Cancer. Cancer Cell. 2018:34(2):186-95.

167. Intlekofer AM, Wang B, Liu H, Shah H, Carmona-Fontaine C, Rustenburg AS, et al. L-2-Hydroxyglutarate production arises from noncanonical enzyme function at acidic pH. Nat Chem Biol. 2017;13(5):494-500

168. Jezek P. 2-Hydroxyglutarate in Cancer Cells. Antioxid Redox Signal. 2020; 33(13):903-26

169. Lee $S$, Hallis SP, Jung KA, Ryu D, Kwak MK. Impairment of HIF-1alphamediated metabolic adaption by NRF2-silencing in breast cancer cells. Redox Biol. 2019:24:101210.

170. Faubert B, Boily G, Izreig S, Griss T, Samborska B, Dong Z, et al. AMPK is a negative regulator of the Warburg effect and suppresses tumor growth in vivo. Cell Metab. 2013;17(1):113-24.

171. Faubert B, Vincent EE, Poffenberger MC, Jones RG. The AMP-activated protein kinase (AMPK) and cancer: many faces of a metabolic regulator. Cancer Lett. 2015;356(2 Pt A):165-70.

172. Sivanand S, Viney I, Wellen KE. Spatiotemporal Control of Acetyl-CoA Metabolism in Chromatin Regulation. Trends Biochem Sci. 2018;43(1): $61-74$

173. Vancura A, Nagar S, Kaur P, Bu P, Bhagwat M, Vancurova I. Reciprocal Regulation of AMPK/SNF1 and Protein Acetylation. Int J Mol Sci. 2018;19(11): 3314

174. Jiang Y, Guo X, Liu L, Rode S, Wang R, Liu H, et al. Metagenomic characterization of lysine acetyltransferases in human cancer and their association with clinicopathologic features. Cancer Sci. 2020;111(5):1829-39.

175. Keating ST, El-Osta A. Epigenetics and metabolism. Circ Res. 2015;116(4): 715-36.

176. Campbell SL, Wellen KE. Metabolic Signaling to the Nucleus in Cancer. Mol Cell. 2018;71(3):398-408.

177. Roche TE, Baker JC, Yan X, Hiromasa Y, Gong X, Peng T, et al. Distinct regulatory properties of pyruvate dehydrogenase kinase and phosphatase isoforms. Prog Nucleic Acid Res Mol Biol. 2001;70:33-75.

178. Kim JW, Tchernyshyov I, Semenza GL, Dang CV. HIF-1-mediated expression of pyruvate dehydrogenase kinase: a metabolic switch required for cellular adaptation to hypoxia. Cell Metab. 2006;3(3):177-85.

179. Papandreou I, Cairns RA, Fontana L, Lim AL, Denko NC. HIF-1 mediates adaptation to hypoxia by actively downregulating mitochondrial oxygen consumption. Cell Metab. 2006;3(3):187-97.

180. Hassannia B, Vandenabeele P, Vanden Berghe T. Targeting Ferroptosis to Iron Out Cancer. Cancer Cell. 2019:35(6):830-49.

181. Conrad M, Pratt DA. The chemical basis of ferroptosis. Nat Chem Biol. 2019; 15(12):1137-47.

182. Diehl FF, Lewis CA, Fiske BP, Vander Heiden MG. Cellular redox state constrains serine synthesis and nucleotide production to impact cell proliferation. Nat Metab. 2019;1(9):861-7. 
183. Nishikawa K, Iwamoto Y, Kobayashi Y, Katsuoka F, Kawaguchi S, Tsujita T, et al. DNA methyltransferase 3a regulates osteoclast differentiation by coupling to an S-adenosylmethionine-producing metabolic pathway. Nat Med. 2015;21(3):281-7.

184. Frau M, Feo F, Pascale RM. Pleiotropic effects of methionine adenosyltransferases deregulation as determinants of liver cancer progression and prognosis. J Hepatol. 2013;59(4):830-41.

185. Doxtader KA, Wang P, Scarborough AM, Seo D, Conrad NK, Nam Y. Structural Basis for Regulation of METTL16, an S-Adenosylmethionine Homeostasis Factor. Mol Cell. 2018;71(6):1001-1011.e1004.

186. Cai J, Mao Z, Hwang JJ, Lu SC. Differential expression of methionine adenosyltransferase genes influences the rate of growth of human hepatocellular carcinoma cells. Cancer Res. 1998;58(7):1444-50.

187. Calvisi DF, Pinna F, Meloni F, Ladu S, Pellegrino R, Sini M, et al. Dualspecificity phosphatase 1 ubiquitination in extracellular signal-regulated kinase-mediated control of growth in human hepatocellular carcinoma. Cancer Res. 2008;68(11):4192-200.

188. Tomasi ML, Ramani K, Lopitz-Otsoa F, Rodríguez MS, Li TW, Ko K, et al. Sadenosylmethionine regulates dual-specificity mitogen-activated protein kinase phosphatase expression in mouse and human hepatocytes. Hepatology. 2010:51(6):2152-61.

189. Karagiota A, Kourti M, Simos G, Mylonis I. HIF-1a-derived cell-penetrating peptides inhibit ERK-dependent activation of HIF-1 and trigger apoptosis of cancer cells under hypoxia. Cell Mol Life Sci. 2019;76(4):809-25.

190. Liu Q, Liu L, Zhao Y, Zhang J, Wang D, Chen J, et al. Hypoxia induces genomic DNA demethylation through the activation of HIF-1a and transcriptional upregulation of MAT2A in hepatoma cells. Mol Cancer Ther 2011;10(6):1113-23.

191. Quinlan CL, Kaiser SE, Bolaños B, Nowlin D, Grantner R, Karlicek-Bryant S, et al. Targeting S-adenosylmethionine biosynthesis with a novel allosteric inhibitor of Mat2A. Nat Chem Biol. 2017;13(7):785-92.

192. Kwon SJ, Lee YJ. Effect of low glutamine/glucose on hypoxia-induced elevation of hypoxia-inducible factor-1alpha in human pancreatic cancer MiaPaCa-2 and human prostatic cancer DU-145 cells. Clin Cancer Res. 2005; 11(13):4694-700.

193. Lloyd MC, Cunningham JJ, Bui MM, Gillies RJ, Brown JS, Gatenby RA Darwinian Dynamics of Intratumoral Heterogeneity: Not Solely Random Mutations but Also Variable Environmental Selection Forces. Cancer Res. 2016;76(11):3136-44.

194. Fan C, Tang Y, Wang J, Xiong F, Guo C, Wang Y, et al. Role of long noncoding RNAs in glucose metabolism in cancer. Mol Cancer. 2017;16(1):130

195. German NJ, Haigis MC. Sirtuins and the Metabolic Hurdles in Cancer. Curr Biol. 2015;25(13):R569-83.

196. Li Z, Zhang H. Reprogramming of glucose, fatty acid and amino acid metabolism for cancer progression. Cell Mol Life Sci. 2016;73(2):377-92.

197. White E, Mehnert JM, Chan CS. Autophagy, Metabolism, and Cancer. Clin Cancer Res. 2015;21(22):5037-46.

198. Massari F, Ciccarese C, Santoni M, lacovelli R, Mazzucchelli R, Piva F, et al. Metabolic phenotype of bladder cancer. Cancer Treat Rev. 2016;45:46-57.

199. Potter M, Newport E, Morten KJ. The Warburg effect: 80 years on. Biochem Soc Trans. 2016:44(5):1499-505.

200. Dauer P, Lengyel E. New Roles for Glycogen in Tumor Progression. Trends Cancer. 2019;5(7):396-9.

201. Théry C, Witwer KW, Aikawa E, Alcaraz MJ, Anderson JD, Andriantsitohaina $R$, et al. Minimal information for studies of extracellular vesicles 2018 (MISE V2018): a position statement of the International Society for Extracellular Vesicles and update of the MISEV2014 guidelines. J Extracell Vesicles. 2018; 7(1):1535750.

202. Reina-Campos M, Moscat J, Diaz-Meco M. Metabolism shapes the tumor microenvironment. Curr Opin Cell Biol. 2017:48:47-53.

203. Vidali S, Aminzadeh S, Lambert B, Rutherford T, Sperl W, Kofler B, et al. Mitochondria: The ketogenic diet--A metabolism-based therapy. Int J Biochem Cell Biol. 2015;63:55-9

204. Zaidi N, Swinnen JV, Smans K. ATP-citrate lyase: a key player in cancer metabolism. Cancer Res. 2012;72(15):3709-14.

205. Chen X, Litzenburger UM, Wei Y, Schep AN, LaGory EL, Choudhry H, et al. Joint single-cell DNA accessibility and protein epitope profiling reveals environmental regulation of epigenomic heterogeneity. Nat Commun. 2018;9(1):4590.

206. Xiao Z, Dai Z, Locasale JW. Metabolic landscape of the tumor microenvironment at single cell resolution. Nat Commun. 2019;10(1): 3763.
207. Xiang L, Mou J, Shao B, Wei Y, Liang H, Takano N, et al. Glutaminase 1 expression in colorectal cancer cells is induced by hypoxia and required for tumor growth, invasion, and metastatic colonization. Cell Death Dis. 2019; 10(2):40.

208. Carracedo A, Cantley LC, Pandolfi PP. Cancer metabolism: fatty acid oxidation in the limelight. Nat Rev Cancer. 2013;13(4):227-32

209. Huang TL, Li X, Zhang L, Sun L, He X, et al. HIF-1-mediated suppression of acyl-CoA dehydrogenases and fatty acid oxidation is critical for cancer progression. Cell Rep. 2014;8(6):1930-42.

210. Du W, Zhang L, Brett-Morris A, Aguila B, Kerner J, Hoppel CL, et al. HIF drives lipid deposition and cancer in ccRCC via repression of fatty acid metabolism. Nat Commun. 2017:8(1):1769.

211. Liu Y, Mao C, Wang M, Liu N, Ouyang L, Liu S, et al. Cancer progression is mediated by proline catabolism in non-small cell lung cancer. Oncogene. 2020;39(11):2358-76.

212. Morello E, Sutti S, Foglia B, Novo E, Cannito S, Bocca C, et al. Hypoxiainducible factor 2 alpha drives nonalcoholic fatty liver progression by triggering hepatocyte release of histidine-rich glycoprotein. Hepatology. 2018:67(6):2196-214.

213. Packer M. Role of Deranged Energy Deprivation Signaling in the Pathogenesis of Cardiac and Renal Disease in States of Perceived Nutrient Overabundance. Circulation. 2020;141(25):2095-105.

214. Yuan H, Su L, Chen WY. The emerging and diverse roles of sirtuins in cancer: a clinical perspective. Onco Targets Ther. 2013;6:1399-416.

215. Houtkooper RH, Pirinen E, Auwerx J. Sirtuins as regulators of metabolism and healthspan. Nat Rev Mol Cell Biol. 2012;13(4):225-38.

216. Roth $M$, Chen WY. Sorting out functions of sirtuins in cancer. Oncogene. 2014;33(13):1609-20.

217. Chen R, Dioum EM, Hogg RT, Gerard RD, Garcia JA. Hypoxia increases sirtuin 1 expression in a hypoxia-inducible factor-dependent manner. J Biol Chem. 2011;286(16):13869-78

218. Koivunen P, Hirsilä M, Remes AM, Hassinen IE, Kivirikko Kl, Myllyharju J. Inhibition of hypoxia-inducible factor (HIF) hydroxylases by citric acid cycle intermediates: possible links between cell metabolism and stabilization of HIF. J Biol Chem. 2007;282(7):4524-32.

219. Sebastián C, Zwaans BM, Silberman DM, Gymrek M, Goren A, Zhong L, et al. The histone deacetylase SIRT6 is a tumor suppressor that controls cancer metabolism. Cell. 2012;151(6):1185-99.

220. Zhong L, D'Urso A, Toiber D, Sebastian C, Henry RE, Vadysirisack DD, et al. The histone deacetylase Sirt6 regulates glucose homeostasis via Hif1alpha. Cell. 2010;140(2):280-93.

221. Hubbi ME, Hu H, Kshitiz IA, Levchenko A, Semenza GL. Chaperone-mediated autophagy targets hypoxia-inducible factor-1a (HIF-1a) for lysosomal degradation. J Biol Chem. 2013;288(15):10703-14.

222. Shankaraiah RC, Veronese A, Sabbioni S, Negrini M. Non-coding RNAs in the reprogramming of glucose metabolism in cancer. Cancer Lett. 2018;419:167-74.

223. Chen Z, Zuo X, Zhang Y, Han G, Zhang L, Wu J, et al. MiR-3662 suppresses hepatocellular carcinoma growth through inhibition of HIF-1a-mediated Warburg effect. Cell Death Dis. 2018;9(5):549.

224. Jin F, Yang R, Wei Y, Wang D, Zhu Y, Wang X, et al. HIF-1a-induced miR23a 27a 24 cluster promotes colorectal cancer progression via reprogramming metabolism. Cancer Lett. 2019;440-441:211-22.

225. Zhou L, Wang Y, Zhou M, Zhang Y, Wang $P$, Li X, et al. HOXA9 inhibits HIF-1a-mediated glycolysis through interacting with CRIP2 to repress cutaneous squamous cell carcinoma development. Nat Commun. 2018; $9(1): 1480$.

226. Monteleone F, Taverna S, Alessandro R, Fontana S. SWATH-MS based quantitative proteomics analysis reveals that curcumin alters the metabolic enzyme profile of CML cells by affecting the activity of miR-22/IPO7/HIF-1a axis. J Exp Clin Cancer Res. 2018;37(1):170.

227. Zhang Y, Liu Y, Xu X. Knockdown of LnCRNA-UCA1 suppresses chemoresistance of pediatric AML by inhibiting glycolysis through the microRNA-125a/hexokinase 2 pathway. J Cell Biochem. 2018;119(7):6296-308.

228. Taddei ML, Giannoni E, Comito G, Chiarugi P. Microenvironment and tumor cell plasticity: an easy way out. Cancer Lett. 2013;341(1):80-96.

229. Janiszewska M. The microcosmos of intratumor heterogeneity: the spacetime of cancer evolution. Oncogene. 2020;39(10):2031-9.

230. Lujambio A, Lowe SW. The microcosmos of cancer. Nature. 2012:482(7385): 347-55.

231. Hui L, Chen Y. Tumor microenvironment: Sanctuary of the devil. Cancer Lett. 2015;368(1):7-13. 
232. Finak G, Bertos N, Pepin F, Sadekova S, Souleimanova M, Zhao H, et al. Stromal gene expression predicts clinical outcome in breast cancer. Nat Med. 2008;14(5):518-27.

233. McCuaig R, Wu F, Dunn J, Rao S, Dahlstrom JE. The biological and clinical significance of stromal-epithelial interactions in breast cancer. Pathology. 2017:49(2):133-40.

234. Quail DF, Joyce JA. Microenvironmental regulation of tumor progression and metastasis. Nat Med. 2013;19(11):1423-37.

235. Garcia-Gomez A, Rodríguez-Ubreva J, Ballestar E. Epigenetic interplay between immune, stromal and cancer cells in the tumor microenvironment. Clin Immunol. 2018;196:64-71.

236. Rodriguez RM, Suarez-Alvarez B, Lopez-Larrea C. Therapeutic Epigenetic Reprogramming of Trained Immunity in Myeloid Cells. Trends Immunol. 2019;40(1):66-80.

237. Ivashkiv LB, Park SH. Epigenetic Regulation of Myeloid Cells. Microbiol Spectr. 2016;4(3).

238. Álvarez-Errico D, Vento-Tormo R, Sieweke M, Ballestar E. Epigenetic control of myeloid cell differentiation, identity and function. Nat Rev Immunol. 2015;15(1):7-17.

239. Delhommeau F, Dupont S, Della Valle V, James C, Trannoy S, Massé A, et al. Mutation in TET2 in myeloid cancers. N Engl J Med. 2009;360(22):2289-301.

240. Ko M, Huang Y, Jankowska AM, Pape UJ, Tahiliani M, Bandukwala HS, et al. Impaired hydroxylation of 5-methylcytosine in myeloid cancers with mutant TET2. Nature. 2010;468(7325):839-43.

241. Figueroa ME, Abdel-Wahab O, Lu C, Ward PS, Patel J, Shih A, et al. Leukemic $\mathrm{IDH} 1$ and $\mathrm{IDH} 2$ mutations result in a hypermethylation phenotype, disrupt TET2 function, and impair hematopoietic differentiation. Cancer Cell. 2010; 18(6):553-67.

242. Zhang Q, Zhao K, Shen Q, Han Y, Gu Y, Li X, et al. Tet2 is required to resolve inflammation by recruiting Hdac2 to specifically repress IL-6. Nature. 2015; 525(7569):389-93.

243. Fischer AP, Miles SL. Silencing HIF-1a induces TET2 expression and augments ascorbic acid induced 5-hydroxymethylation of DNA in human metastatic melanoma cells. Biochem Biophys Res Commun. 2017;490(2):176-81.

244. Gabrilovich DI, Ostrand-Rosenberg S, Bronte V. Coordinated regulation of myeloid cells by tumours. Nat Rev Immunol. 2012;12(4):253-68.

245. Salminen A, Kaarniranta K, Kauppinen A. The role of myeloid-derived suppressor cells (MDSC) in the inflammaging process. Ageing Res Rev. 2018;48:1-10.

246. Ohl K, Tenbrock K. Reactive Oxygen Species as Regulators of MDSCMediated Immune Suppression. Front Immunol. 2018;9:2499.

247. Obermajer N, Muthuswamy R, Lesnock J, Edwards RP, Kalinski P. Positive feedback between PGE2 and COX2 redirects the differentiation of human dendritic cells toward stable myeloid-derived suppressor cells. Blood. 2011; 118(20):5498-505.

248. Rodríguez-Ubreva J, Català-Moll F, Obermajer N, Álvarez-Errico D, Ramirez RN, Company C, et al. Prostaglandin E2 Leads to the Acquisition of DNMT3A-Dependent Tolerogenic Functions in Human Myeloid-Derived Suppressor Cells. Cell Rep. 2017;21(1):154-67.

249. Lachance G, Uniacke J, Audas TE, Holterman CE, Franovic A, Payette J, et al. DNMT3a epigenetic program regulates the HIF-2a oxygen-sensing pathway and the cellular response to hypoxia. Proc Natl Acad Sci U S A. 2014;111(21):7783-8.

250. Mishra R, Haldar S, Placencio V, Madhav A, Rohena-Rivera K, Agarwal P, et al. Stromal epigenetic alterations drive metabolic and neuroendocrine prostate cancer reprogramming. J Clin Invest. 2018;128(10):4472-84.

251. Lambrechts D, Wauters E, Boeckx B, Aibar S, Nittner D, Burton O, et al. Phenotype molding of stromal cells in the lung tumor microenvironment. Nat Med. 2018;24(8):1277-89.

252. Xu L, Deng Q, Pan Y, Peng M, Wang X, song $L$, et al. Cancer-associated fibroblasts enhance the migration ability of ovarian cancer cells by increasing EZH2 expression. Int J Mol Med. 2014;33(1):91-6.

253. Bonnans C, Chou J, Werb Z. Remodelling the extracellular matrix in development and disease. Nat Rev Mol Cell Biol. 2014;15(12):786-801.

254. Herrera J, Henke CA, Bitterman PB. Extracellular matrix as a driver of progressive fibrosis. J Clin Invest. 2018;128(1):45-53.

255. Natarajan S, Foreman KM, Soriano MI, Rossen NS, Shehade H, Fregoso DR, et al. Collagen Remodeling in the Hypoxic Tumor-Mesothelial Niche Promotes Ovarian Cancer Metastasis. Cancer Res. 2019;79(9):2271-84.

256. Amelio I, Mancini M, Petrova V, Cairns RA, Vikhreva P, Nicolai S, et al. p53 mutants cooperate with HIF-1 in transcriptional regulation of extracellular matrix components to promote tumor progression. Proc Natl Acad Sci U S A. 2018;115(46):E10869-e10878.
257. Gilkes DM, Bajpai S, Chaturvedi P, Wirtz D, Semenza GL. Hypoxia-inducible factor 1 (HIF-1) promotes extracellular matrix remodeling under hypoxic conditions by inducing P4HA1, P4HA2, and PLOD2 expression in fibroblasts. J Biol Chem. 2013;288(15):10819-29.

258. Piperigkou Z, Karamanos NK. Dynamic Interplay between miRNAs and the Extracellular Matrix Influences the Tumor Microenvironment. Trends Biochem Sci. 2019;44(12):1076-88.

259. Ullah I, Abu-Dawud R, Busch JF, Rabien A, Erguen B, Fischer I, et al. VEGF Supplemented extracellular matrix is sufficient to induce endothelial differentiation of human iPSC. Biomaterials. 2019;216:119283.

260. Apte RS, Chen DS, Ferrara N. VEGF in Signaling and Disease: Beyond Discovery and Development. Cell. 2019;176(6):1248-64.

261. Viallard C, Larrivée B. Tumor angiogenesis and vascular normalization: alternative therapeutic targets. Angiogenesis. 2017;20(4):409-26.

262. Vecchione A, Belletti B, Lovat F, Volinia S, Chiappetta G, Giglio S, et al. A microRNA signature defines chemoresistance in ovarian cancer through modulation of angiogenesis. Proc Natl Acad Sci U S A. 2013;110(24):9845-50.

263. Sabry D, El-Deek SEM, Maher M, El-Baz MAH, El-Bader HM, Amer E, et al. Role of miRNA-210, miRNA-21 and miRNA-126 as diagnostic biomarkers in colorectal carcinoma: impact of HIF-1a-VEGF signaling pathway. Mol Cell Biochem. 2019:454(1-2):177-89.

264. Fasanaro P, D'Alessandra Y, Di Stefano V, Melchionna R, Romani S, Pompilio $\mathrm{G}$, et al. MicroRNA-210 modulates endothelial cell response to hypoxia and inhibits the receptor tyrosine kinase ligand Ephrin-A3. J Biol Chem. 2008; 283(23):15878-83.

265. Frediani JN, Fabbri M. Essential role of miRNAs in orchestrating the biology of the tumor microenvironment. Mol Cancer. 2016;15(1):42.

266. Chang SH, Kanasaki K, Gocheva V, Blum G, Harper J, Moses MA, et al. VEGFA induces angiogenesis by perturbing the cathepsin-cysteine protease inhibitor balance in venules, causing basement membrane degradation and mother vessel formation. Cancer Res. 2009;69(10):4537-44.

267. Senger DR, Davis GE. Angiogenesis. Cold Spring Harb Perspect Biol. 2011; 3(8):a005090.

268. Rahbari NN, Kedrin D, Incio J, Liu H, Ho WW, Nia HT, et al. Anti-VEGF therapy induces ECM remodeling and mechanical barriers to therapy in colorectal cancer liver metastases. Sci Transl Med. 2016:8(360):360ra135.

269. Rankin EB, Giaccia AJ. Hypoxic control of metastasis. Science. 2016; 352(6282):175-80.

270. Schito L, Rey S. Hypoxic pathobiology of breast cancer metastasis. Biochim Biophys Acta Rev Cancer. 2017;1868(1):239-45.

271. Nobre AR, Entenberg D, Wang Y, Condeelis J, Aguirre-Ghiso JA. The Different Routes to Metastasis via Hypoxia-Regulated Programs. Trends Cell Biol. 2018;28(11):941-56

272. Chatterjee A, Rodger EJ, Eccles MR. Epigenetic drivers of tumourigenesis and cancer metastasis. Semin Cancer Biol. 2018:51:149-59.

273. Pharoah PD, Guilford P, Caldas C. Incidence of gastric cancer and breast cancer in $\mathrm{CDH} 1$ (E-cadherin) mutation carriers from hereditary diffuse gastric cancer families. Gastroenterology. 2001;121(6):1348-53.

274. Lamouille S, Xu J, Derynck R. Molecular mechanisms of epithelialmesenchymal transition. Nat Rev Mol Cell Biol. 2014;15(3):178-96.

275. Kozaki K, Inazawa J. Tumor-suppressive microRNA silenced by tumor-specific DNA hypermethylation in cancer cells. Cancer Sci. 2012;103(5):837-45.

276. Kozaki K, Imoto I, Mogi S, Omura K, Inazawa J. Exploration of tumorsuppressive microRNAs silenced by DNA hypermethylation in oral cancer. Cancer Res. 2008:68(7):2094-105.

277. Luo W, Chang R, Zhong J, Pandey A, Semenza GL. Histone demethylase JMJD2C is a coactivator for hypoxia-inducible factor 1 that is required for breast cancer progression. Proc Natl Acad Sci U S A. 2012;109(49): E3367-76.

278. Ma L, Qi T, Wang S, Hao M, Sakhawat A, Liang T, et al. Tet methylcytosine dioxygenase 1 promotes hypoxic gene induction and cell migration in colon cancer. J Cell Physiol. 2019;234(5):6286-97.

279. Kao SH, Wu KJ, Lee WH. Hypoxia, Epithelial-Mesenchymal Transition, and TET-Mediated Epigenetic Changes. J Clin Med. 2016;5(2):24.

280. Tao QF, Yuan SX, Yang F, Yang S, Yang Y, Yuan JH, et al. Aldolase B inhibits metastasis through Ten-Eleven Translocation 1 and serves as a prognostic biomarker in hepatocellular carcinoma. Mol Cancer. 2015;14:170.

281. Wu J, Li H, Shi M, Zhu Y, Ma Y, Zhong Y, et al. TET1-mediated DNA hydroxymethylation activates inhibitors of the $W n t / \beta$-catenin signaling pathway to suppress EMT in pancreatic tumor cells. J Exp Clin Cancer Res. 2019;38(1):348. 
282. Hsu CH, Peng KL, Kang ML, Chen YR, Yang YC, Tsai CH, et al. TET1 suppresses cancer invasion by activating the tissue inhibitors of metalloproteinases. Cell Rep. 2012;2(3):568-79.

283. Lonser RR, Glenn GM, Walther M, Chew EY, Libutti SK, Linehan WM, et al. von Hippel-Lindau disease. Lancet. 2003;361(9374):2059-67.

284. Vanharanta S, Shu W, Brenet F, Hakimi AA, Heguy A, Viale A, et al. Epigenetic expansion of VHL-HIF signal output drives multiorgan metastasis in renal cancer. Nat Med. 2013;19(1):50-6.

285. Dongre A, Weinberg RA. New insights into the mechanisms of epithelialmesenchymal transition and implications for cancer. Nat Rev Mol Cell Biol. 2019;20(2):69-84.

286. Wu MZ, Tsai YP, Yang MH, Huang CH, Chang SY, Chang CC, et al. Interplay between HDAC3 and WDR5 is essential for hypoxia-induced epithelialmesenchymal transition. Mol Cell. 2011;43(5):811-22.

287. Huang $\mathrm{H}$, Weng $\mathrm{H}$, Chen J. m(6) A Modification in Coding and Non-coding RNAs: Roles and Therapeutic Implications in Cancer. Cancer Cell. 2020;37(3): 270-88

288. Yu X, Hu L, Li S, Shen J, Wang D, Xu R, et al. Long non-coding RNA Taurine upregulated gene 1 promotes osteosarcoma cell metastasis by mediating HIF-1a via miR-143-5p. Cell Death Dis. 2019;10(4):280.

289. Lin J, Cao S, Wang Y, Hu Y, Liu H, Li J, et al. Long non-coding RNA UBE2CP3 enhances HCC cell secretion of VEGFA and promotes angiogenesis by activating ERK1/2/HIF-1a/VEGFA signalling in hepatocellular carcinoma. J Exp Clin Cancer Res. 2018:37(1):113.

290. Mor M, Nardone S, Sams DS, Elliott E. Hypomethylation of miR-142 promoter and upregulation of microRNAs that target the oxytocin receptor gene in the autism prefrontal cortex. Mol Autism. 2015;6:46.

291. Leichter AL, Sullivan MJ, Eccles MR, Chatterjee A. MicroRNA expression patterns and signalling pathways in the development and progression of childhood solid tumours. Mol Cancer. 2017;16(1):15.

292. Shenoy N, Pagliaro L. Sequential pathogenesis of metastatic VHL mutant clear cell renal cell carcinoma: putting it together with a translational perspective. Ann Oncol. 2016;27(9):1685-95.

293. Hanahan D, Weinberg RA. Hallmarks of cancer: the next generation. Cell. 2011;144(5):646-74.

294. Shweiki D, Itin A, Soffer D, Keshet E. Vascular endothelial growth factor induced by hypoxia may mediate hypoxia-initiated angiogenesis. Nature. 1992;359(6398):843-5.

295. Koch S, Claesson-Welsh L. Signal transduction by vascular endothelial growth factor receptors. Cold Spring Harb Perspect Med. 2012;2(7):a006502.

296. Alon T, Hemo I, Itin A, Pe'er J, Stone J, Keshet E. Vascular endothelial growth factor acts as a survival factor for newly formed retinal vessels and has implications for retinopathy of prematurity. Nat Med. 1995;1(10):1024-8.

297. Beck B, Driessens G, Goossens S, Youssef KK, Kuchnio A, Caauwe A, et al. A vascular niche and a VEGF-Nrp1 loop regulate the initiation and stemness of skin tumours. Nature. 2011;478(7369):399-403.

298. Bedard PL, Hyman DM, Davids MS, Siu LL. Small molecules, big impact: 20 years of targeted therapy in oncology. Lancet. 2020;395(10229):1078-88.

299. Favier B, Alam A, Barron P, Bonnin J, Laboudie P, Fons P, et al. Neuropilin-2 interacts with VEGFR-2 and VEGFR-3 and promotes human endothelial cell survival and migration. Blood. 2006;108(4):1243-50.

300. Murugesan T, Rajajeyabalachandran G, Kumar S, Nagaraju S, Jegatheesan SK. Targeting HIF-2a as therapy for advanced cancers. Drug Discov Today. 2018. 23(7):1444-51.

301. Ban HS, Uto Y, Won M, Nakamura H. Hypoxia-inducible factor (HIF) inhibitors: a patent survey (2011-2015). Expert Opin Ther Pat. 2016;26(3): 309-22.

302. Nakazawa MS, Eisinger-Mathason TS, Sadri N, Ochocki JD, Gade TP, Amin RK, et al. Epigenetic re-expression of HIF-2a suppresses soft tissue sarcoma growth. Nat Commun. 2016;7:10539.

303. Westerlund I, Shi Y, Toskas K, Fell SM, Li S, Surova O, et al. Combined epigenetic and differentiation-based treatment inhibits neuroblastoma tumor growth and links HIF2a to tumor suppression. Proc Natl Acad Sci U S A. 2017;114(30):E6137-e6146.

304. Chakraborty AA. Coalescing lessons from oxygen sensing, tumor metabolism, and epigenetics to target VHL loss in kidney cancer. Semin Cancer Biol. 2020;S1044-579X(20)30078-X. https://doi.org/10.1016/j. semcancer.2020.03.012

305. Hsieh JJ, Le VH, Oyama T, Ricketts CJ, Ho TH, Cheng EH. Chromosome 3p Loss-Orchestrated VHL, HIF, and Epigenetic Deregulation in Clear Cell Renal Cell Carcinoma. J Clin Oncol. 2018;36:Jco2018792549.
306. Cho H, Kaelin WG. Targeting HIF2 in Clear Cell Renal Cell Carcinoma. Cold Spring Harb Symp Quant Biol. 2016;81:113-21.

307. Okazaki A, Gameiro PA, Christodoulou D, Laviollette L, Schneider M, Chaves F, et al. Glutaminase and poly (ADP-ribose) polymerase inhibitors suppress pyrimidine synthesis and VHL-deficient renal cancers. J Clin Invest. 2017; 127(5):1631-45.

308. Qu A, Taylor M, Xue X, Matsubara T, Metzger D, Chambon P, et al. Hypoxiainducible transcription factor 2alpha promotes steatohepatitis through augmenting lipid accumulation, inflammation, and fibrosis. Hepatology. 2011;54(2):472-83.

309. Jain $I H$, Calvo SE, Markhard AL, Skinner OS, T. L. To, Ast T, et al. Genetic Screen for Cell Fitness in High or Low Oxygen Highlights Mitochondrial and Lipid Metabolism. Cell. 2020;181(3):716-727.e11.

310. Liu X, Zhang X, Peng Z, Li C, Wang Z, Wang C, et al. Deubiquitylase OTUD6B Governs pVHL Stability in an Enzyme-Independent Manner and Suppresses Hepatocellular Carcinoma Metastasis. Adv Sci (Weinh). 2020;7(8): 1902040.

311. Stathis A, Bertoni F. BET Proteins as Targets for Anticancer Treatment. Cancer Discov. 2018;8(1):24-36.

312. Petretich M, Demont EH, Grandi P. Domain-selective targeting of BET proteins in cancer and immunological diseases. Curr Opin Chem Biol. 2020; 57:184-93.

313. Dong $X$, Hu X, Chen J, Hu D, Chen LF. BRD4 regulates cellular senescence in gastric cancer cells via E2F/miR-106b/p21 axis. Cell Death Dis. 2018;9(2):203.

314. Zengerle M, Chan KH, Ciulli A. Selective Small Molecule Induced Degradation of the BET Bromodomain Protein BRD4. ACS Chem Biol. 2015; 10(8):1770-7.

315. Yin M, Guo Y, Hu R, Cai WL, Li Y, Pei S, et al. Potent BRD4 inhibitor suppresses cancer cell-macrophage interaction. Nat Commun. 1833;11(1): 2020.

316. Wu SY, Lee AY, Lai HT, Zhang H, Chiang CM. Phospho switch triggers Brd4 chromatin binding and activator recruitment for gene-specific targeting. Mol Cell. 2013:49(5):843-57.

317. Chen $Y$, Zhang B, Bao L, Jin L, Yang M, Peng Y, et al. ZMYND8 acetylation mediates HIF-dependent breast cancer progression and metastasis. J Clin Invest. 2018;128(5):1937-55.

318. da Motta LL, Ledaki I, Purshouse K, Haider S, De Bastiani MA, Baban D, et al. The BET inhibitor JQ1 selectively impairs tumour response to hypoxia and downregulates CA9 and angiogenesis in triple negative breast cancer. Oncogene. 2017;36(1):122-32.

319. Nicodeme E, Jeffrey KL, Schaefer U, Beinke S, Dewell S, Chung CW, et al. Suppression of inflammation by a synthetic histone mimic. Nature. 2010; 468(7327):1119-23.

320. Ferri E, Petosa C, McKenna CE. Bromodomains: Structure, function and pharmacology of inhibition. Biochem Pharmacol. 2016;106:1-18.

321. Haber T, Cornejo YR, Aramburo S, Flores L, Cao P, Liu A, et al. Specific targeting of ovarian tumor-associated macrophages by large, anionic nanoparticles. Proc Natl Acad Sci U S A. 2020;117(33):19737-45.

322. Stockwell BR, Jiang X. The Chemistry and Biology of Ferroptosis. Cell Chem Biol. 2020;27(4):365-75.

323. Mao C, Wang X, Liu Y, Wang M, Yan B, Jiang Y, et al. A G3BP1-Interacting IncRNA Promotes Ferroptosis and Apoptosis in Cancer via Nuclear Sequestration of p53. Cancer Res. 2018;78(13):3484-96.

324. Yang $R$, Liu $N$, Chen $L$, Jiang $Y$, Shi $Y$, Mao $C$, et al. GIAT4RA functions as a tumor suppressor in non-small cell lung cancer by counteracting Uchl3mediated deubiquitination of LSH. Oncogene. 2019;38(46):7133-45.

325. Wu Y, Zhang S, Gong X, Tam S, Xiao D, Liu S, et al. The epigenetic regulators and metabolic changes in ferroptosis-associated cancer progression. Mol Cancer. 2020;19(1):39.

\section{Publisher's Note}

Springer Nature remains neutral with regard to jurisdictional claims in published maps and institutional affiliations. 